\title{
Nordic Seas and Arctic Ocean CFC data in CARINA
}

\author{
E. Jeansson ${ }^{1}$, K. A. Olsson ${ }^{2, *}$, T. Tanhua ${ }^{3}$, and J. L. Bullister ${ }^{4}$ \\ ${ }^{1}$ Bjerknes Centre for Climate Research, Uni Research, Bergen, Norway \\ ${ }^{2}$ Department of Chemistry, University of Gothenburg, Göteborg, Sweden \\ ${ }^{3}$ Leibniz-Institut für Meereswissenshaften, Marine Biogeochemie, Kiel, Germany \\ ${ }^{4}$ Pacific Marine Environmental Laboratory, NOAA, Seattle, Washington, USA \\ *present address: Volvo Technology Corporation, Environment \& Chemistry, Gothenburg, Sweden
}

Received: 22 September 2009 - Published in Earth Syst. Sci. Data Discuss.: 16 October 2009

Revised: 1 February 2010 - Accepted: 9 February 2010 - Published: 15 February 2010

\begin{abstract}
Water column data of carbon and carbon relevant hydrographic and hydrochemical parameters have been retrieved from a large number of cruises and collected into a new database called CARINA (CARbon IN the Atlantic). These data have been merged into three sets of files, one for each of the three CARINA regions; the Arctic Mediterranean Seas (AMS), the Atlantic (ATL) and the Southern Ocean (SO). The first part of the CARINA database consists of three files, one for each CARINA region, containing the original, nonadjusted cruise data sets, including data quality flags for each measurement. These data have then been subject to rigorous quality control (QC) in order to ensure highest possible quality and consistency. The data for most of the parameters included were examined in order to quantify systematic biases in the reported values, i.e. secondary quality control. Significant biases have been corrected for in the second part of the CARINA data product. This consists of three files, one for each CARINA region, which contain adjustments to the original data values based on recommendations from the CARINA QC procedures, along with calculated and interpolated values for some missing parameters.
\end{abstract}

Here we present an overview of the QC of the $\mathrm{CFC}$ data for the AMS region, including the chlorofluorocarbons CFC-11, CFC-12 and CFC-113, as well as carbon tetrachloride $\left(\mathrm{CCl}_{4}\right)$. The Arctic Mediterranean Seas is comprised of the Arctic Ocean and the Nordic Seas, and the quality control was carried out separately in these two areas. For the secondary QC of the CFCs we used a combination of tools, including the evaluation of depth profiles and CFC ratios, surface saturations and a crossover analysis. This resulted in a multiplicative adjustment of data from some cruises, while other data were flagged to be of questionable quality, which excluded them from the final data product.

\section{Data coverage and parameter measured}

Repository-Reference: doi: CARINA.AMS.V1.2, doi:10.3334/CDIAC/otg.CARINA.AMS.V1.2

Available at:

http://cdiac.ornl.gov/oceans/CARINA/Carina_inv.html

Coverage: Nordic Seas: $59.60-82.35^{\circ} \mathrm{N}, 35.23^{\circ} \mathrm{W}-28^{\circ} \mathrm{E}$;

Arctic Ocean: $60.7-90^{\circ} \mathrm{N}$, circumpolar

Location Name: Nordic Seas; Arctic Ocean
Nordic Seas: Date/Time Start: 1982-02-28;

Nordic Seas: Date/Time End: 2003-10-13

Arctic Ocean: Date/Time Start: 1991-07-26;

Arctic Ocean: Date/Time End: 1997-10-15

Correspondence to: E. Jeansson

(emil.jeansson@uni.no) 


\begin{tabular}{lllll}
\hline $\begin{array}{l}\text { Data Product } \\
\text { Parameter Name }\end{array}$ & $\begin{array}{l}\text { Data Product } \\
\text { Flag name }\end{array}$ & $\begin{array}{l}\text { Exchange File } \\
\text { Parameter Name }\end{array}$ & $\begin{array}{l}\text { Exchange File } \\
\text { Flag Name }\end{array}$ & Units \\
\hline $\begin{array}{l}\text { station } \\
\text { day }\end{array}$ & & STANBR & & \\
month & & DATE & & \\
year & & DATE & & \\
latitude & & DATE & & decimal degrees \\
longitude & & LATITUDE & & decimal degrees \\
cruiseno & & LONGITUDE & & \\
depth & & & Meters \\
temperature & & CTDTMP & & \\
salinity & sf & SALNTY & SALNTY_FLAG_W & \\
ctdsal & ctdsf & CTDSAL & CTDSAL_FLAG_W & \\
pressure & & CTDPRS & & decibars \\
cfc11 & cfc11f & & picomole $\mathrm{kg}^{-1}$ \\
cfc12 & cfc12f & & & picomole $\mathrm{kg}^{-1}$ \\
cfc113 & cfc113f & & picomole $\mathrm{kg}^{-1}$ \\
cc14 & ccl4f & & picomole $\mathrm{kg}^{-1}$ \\
pf11 & & & ppt \\
pf12 & & & ppt \\
pf113 & & & ppt \\
pcc14 & & & ppt \\
\hline & & & \\
\end{tabular}

pf11, pf12, pf113 and pccl4 are the partial pressures of the compounds, expressed in ppt (10-12 atmospheres).

For a complete list of all parameters available in CARINA see Key et al. (2009). Note the different names for the parameters in the Exchange files (the individual cruise files) and the merged data product.

\section{Introduction}

CARINA (CARbon IN the Atlantic) is a database of carbon relevant data from hydrographic cruises in the Arctic, Atlantic and Southern Oceans. The database was initiated as an essentially informal, unfunded project in Kiel, Germany in 1999, with the main goal to create a database of carbon relevant variables in the ocean to be used for accurate assessments of oceanic carbon inventories and uptake rates. Not only the collection of data, but also the quality control of the data has been a main focus of the project. During the project, both primary and secondary quality control (QC) of the data has been performed. The CARINA database consists of essentially two parts: The first part is the individual cruise files containing all the data that were reported for discrete water samples collected during the cruise, along with the corresponding data quality flag for each measurement. In most cases, the groups directly involved in making the measurements provided the data values contained in these files. These files are in WOCE Hydrographic Program (WHP) exchange format where the first lines consist of the condensed metadata. Information on these file formats can be found in the WHP manuals at http://whpo.ucsd.edu/manuals.html. The values in these files are based on the direct measurements made on the individual water samples and are not calculated from other parameters or interpolated from surrounding measurements; i.e. no adjustments have been applied to the reported values. In many cases there are more parameters (such as ${ }^{14} \mathrm{C},{ }^{13} \mathrm{C}$ and $\mathrm{SF}_{6}$ ) reported in the individual cruise files than has been included in the secondary QC. The second part of the CARINA database consists of three merged data files, one for each region, and contains only the data considered being of "good" quality. These files include: data values from the original cruise files, some of which have been adjusted based on the secondary QC processes as part of CARINA (see Key et al., 2009); interpolated values for nutrients, oxygen and salinity if those data were missing for individual samples and if interpolation could be made according to criteria described in Key et al. (2009). It also contains calculated carbon parameters when applicable, e.g., if total dissolved inorganic carbon $\left(\mathrm{TCO}_{2}\right)$ and alkalinity (TA) were measured, $\mathrm{pH}$ was calculated from these.

Here we describe the data and present an overview of the secondary QC of the chlorofluorocarbon (CFC) compounds CFC-11, CFC-12 and CFC-113, and carbon tetrachloride $\left(\mathrm{CCl}_{4}\right)$. In this study we treat $\mathrm{CCl}_{4}$ as a member of the CFC family of chemical compounds, despite not being a "true" CFC. All the Arctic Mediterranean Seas (AMS) CFC values in the merged data file have been adjusted according to the values in Table 1 (Nordic Seas) and Table 2 (Arctic Ocean). For an overview of all parameters and adjustments of the AMS data the reader is referred to Olsen et al. (2009) and Jutterström et al. (2010). Information on the secondary QC of oxygen, nutrients, $\mathrm{TCO}_{2}$ and TA data is found in Falck and Olsen (2009), Olafsson and Olsen (2010), Olsen (2009a and b), respectively. More details to the 
Table 1. CARINA cruises with CFC data in the Nordic Seas. ND denotes "no data", i.e. the parameter was not measured. Adjustments for the CFCs are multiplicative and the presented numbers been applied in the merged data product. Flag 3 means that the data are of questionable quality and are not included in the merged data product.

\begin{tabular}{|c|c|c|c|c|c|c|c|c|}
\hline Cruise No. ${ }^{a}$ & EXPOCODE & Year & Country/Institute & P.I. & CFC11 & $\mathrm{CFC} 12$ & CFC113 & $\mathrm{CCl}_{4}$ \\
\hline 36 & 18HU19820228 & 1982 & USA/SIO & R. Weiss/D. Wallace & 1.05 & 1 & ND & ND \\
\hline 67 & $316 \mathrm{~N} 20020530$ & 2002 & USA/LDEO & W. Smethie & 1 & 1 & 0.9 & ND \\
\hline 91 & 34AR19970805 & 1997 & Sweden/UGOT & T. Tanhua/A. Olsson & $0.95^{\mathrm{b}}$ & 1 & 1 & 1 \\
\hline 117 & 58AA19940224 & 1994 & Sweden/UGOT & E. Fogelqvist & 1 & Flag 3 & ND & 0.9 \\
\hline 119 & 58AA19950217 & 1995 & Sweden/UGOT & A. Olsson/T. Tanhua & 1.1 & Flag 3 & Flag 3 & ND \\
\hline 120 & 58AA19961121 & 1996 & Sweden/UGOT & E. Fogelqvist/T. Tanhua/A. Olsson & 1 & 1 & ND & ND \\
\hline 125 & 58AA20010527 & 2001 & Sweden/UGOT & A. Olsson/E. Jeansson & 1 & 0.95 & ND & ND \\
\hline 128 & 58GS20030922 & 2003 & Sweden/UGOT & A. Olsson/E. Jeansson & 1 & 0.95 & ND & ND \\
\hline 129 & 58JH19911105 & 1991 & USA/BNL; USA/PMEL & D. Wallace/J. Bullister & 1 & ND & ND & 1 \\
\hline 131 & 58JH19921105 & 1992 & USA/BNL; USA/PMEL & D. Wallace/J. Bullister & 0.95 & 1 & 1 & 1.05 \\
\hline 133 & 58JH19931106 & 1993 & USA/BNL; USA/PMEL & D. Wallace/J. Bullister & 1 & 1 & 0.95 & ND \\
\hline 135 & $58 \mathrm{JH} 19940723$ & 1994 & Sweden/UGOT & E. Fogelqvist/T. Tanhua & Flag 3 & Flag 3 & Flag 3 & Flag 3 \\
\hline 136 & 58JH19941028 & 1994 & USA/BNL; USA/PMEL & D. Wallace/J. Bullister & 1 & 1 & 1 & 1 \\
\hline 138 & 58JH19951108 & 1995 & USA/BNL; USA/PMEL & D. Wallace/J. Bullister & 1 & 0.95 & 1 & 1 \\
\hline 140 & 58JH19961030 & 1996 & USA/PMEL; USA/BNL & J. Bullister/D. Wallace & 1 & 1 & 1.05 & 1 \\
\hline 141 & $58 \mathrm{JH} 19970414$ & 1997 & USA/PMEL; USA/BNL & J. Bullister/D. Wallace & 1 & 1 & 1 & 1 \\
\hline 142 & 58JH19980801 & 1998 & USA/PMEL; USA/BNL & J. Bullister/D. Wallace & 1 & 1.05 & 1.1 & 1 \\
\hline 143 & 58JH19990615 & 1999 & USA/PMEL; USA/BNL & J. Bullister/D. Wallace & 1 & 1 & Flag 3 & 1 \\
\hline 144 & $58 \mathrm{JH} 20000527$ & 2000 & USA/PMEL; USA/BNL & J. Bullister/D. Wallace & 1 & 1.05 & Flag 3 & 0.95 \\
\hline 176 & 74JC19960720 & 1996 & Sweden/UGOT & E. Fogelqvist/A. Olsson & 1 & 1 & 1 & Flag 3 \\
\hline 179 & 77DN20020420 & 2002 & Canada/BIO & P. Jones & 1 & 1 & Flag $3^{c}$ & Flag $3^{\mathrm{c}}$ \\
\hline
\end{tabular}

${ }^{\text {a }}$ CARINA cruise number is cruise identifier in merged data file.

${ }^{\mathrm{b}}$ Adjustment recommended by the North Atlantic group.

${ }^{c}$ Oden: Flagged 3 by R. Key during the primary QC process (Key et al., 2009).

Abbreviations: BIO=Bedford Institute of Oceanography (Canada); BNL=Brookhaven National Laboratory (USA); LDEO=Lamont Doherty Earth Observatory (USA); PMEL=Pacific Marine Environmental Laboratory, NOAA (USA); SIO=Scripps Institution of Oceanography (USA); UGOT=University of Gothenburg (Sweden).

Table 2. CARINA cruises with CFC data in the Arctic Ocean. ND denotes "no data", i.e. the parameter was not measured; Adjustments for the CFCs are multiplicative. Flag 3 means that the data are of questionable quality and are not included in the merged data product.

\begin{tabular}{|c|c|c|c|c|c|c|c|c|c|}
\hline Cruise No. & EXPOCODE & Year & Country/Institute & P.I. & Sampled area & CFC11 & $\mathrm{CFC} 12$ & CFC113 & $\mathrm{CCl}_{4}$ \\
\hline 2 & 06AQ19930806 & 1993 & USA/LDEO & W. Smethie & Laptev Sea & 1 & 1 & 1 & ND \\
\hline 3 & 06AQ19960712 & 1996 & Canada/BIO;Germany/IfMK & P. Jones/M. Rhein & Laptev and Kara Seas & 1 & 1 & ND & 1 \\
\hline 47 & 18SN19940724 & 1994 & Canada/BIO & P. Jones & Canadian Basin & 1.05 & 1 & Flag 3 & 1 \\
\hline 48 & $18 \mathrm{SN} 19970803^{\mathrm{a}}$ & 1997 & Canada/BIO & P. Jones/K. Azetsu-Scott & Baffin Bay & 1 & 1 & 1 & 1 \\
\hline 49 & $18 \mathrm{SN} 19970831^{\mathrm{a}}$ & 1997 & Canada/BIO & P. Jones/K. Azetsu-Scott & Canadian archipelago & 1 & 1 & 1 & 1 \\
\hline 50 & $18 \mathrm{SN} 19970924^{\mathrm{a}}$ & 1997 & Canada/BIO & P. Jones/K. Azetsu-Scott & Canada Basin & 1 & 1 & 1 & 1 \\
\hline 177 & 77DN19910726 & 1991 & Canada/BIO & P. Jones & Eurasian Basin & 1 & 1 & ND & 1 \\
\hline
\end{tabular}

a The three 1997 cruises is really one cruise, divided in three parts.

Abbreviations: $\mathrm{BIO}=$ Bedford Institute of Oceanography (Canada); IfMK=Institut für Meereskunde, Kiel (Germany); LDEO=Lamont Doherty Earth Observatory (USA).

process can be found on the CARINA website at CDIAC, http://cdiac.ornl.gov/oceans/CARINA/Carina_inv.html.

\section{Data Provenance and Structure}

The cruise on C.S.S. Hudson in the winter of 1982 collected an extensive set of CFC samples in the Greenland and
Norwegian Seas (Bullister and Weiss, 1983). After that a decade passed without any CFC sampling in the AMS region, i.e. the Arctic Ocean and the Nordic Seas. In 1991 annual measurements of transient tracers commenced in the Nordic Seas as a part of the Atlantic Climate Change Program (ACCP) and later by CLIVAR (Climate Variability and Prediction) Atlantic activities. These measurements went on 


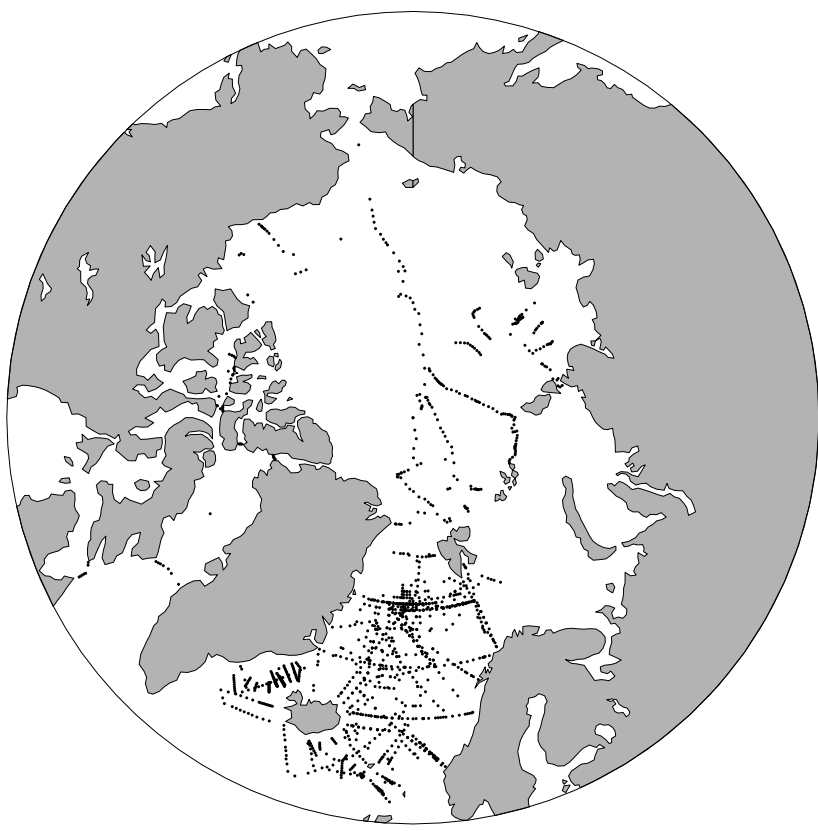

Figure 1. Map of the Arctic Mediterranean Seas showing all stations with CFC data in the CARINA data collection.

until 2000 within the repeated hydrographic surveys conducted by the Institute of Marine Research (IMR) in Bergen, Norway (Bönisch et al., 1997; Karstensen et al., 2005; see also Olsen et al., 2009). The CFC measurement program was headed by Brookhaven National Laboratory (BNL) between 1991 and 1995 and by NOAA's Pacific Marine Environmental Laboratory (PMEL) between 1996 and 2000 (e.g., Karstensen et al., 2005). Between 1995 and 2003 considerable CFC sampling was also conducted during the EU funded projects ESOP, ESOP II and TRACTOR, mostly by University of Gothenburg (UGOT). The data from these projects are all included in the Nordic Seas part of the CARINA database, where 21 out of the total 35 cruises contain CFC data. In addition the CARINA data set includes 26 cruises from the Arctic Ocean, and seven of those contain CFC data, collected between 1991 and 1997. These cruises sampled the different basins of the Arctic Ocean, but also the Baffin Bay and the Canadian archipelago. The Arctic Ocean data are described in the end of this paper (Sect. 7).

An overview of the Nordic Seas data included in the secondary QC can be found in Table 1, and the station positions in Fig. 1. The CFC data in the CARINA data set have all been determined by a similar analytical method, based on a purge and trap pre-treatment technique in combination with gas chromatography with electron capture detection (e.g., Bullister and Weiss, 1983; Fogelqvist, 1999). The values have been calibrated against gas-phase standards. The precision of the analysis is typically between 1 and $2 \%$, and the overall accuracy before secondary QC is typically estimated to be roughly twice that. All results are reported on the SIO-98 cal- ibration scale (http://bluemoon.ucsd.edu/pub/cfchist/). More information of the CFC data from each individual cruise can be found in the metadata accompanying the individual cruise files, http://cdiac.ornl.gov/oceans/CARINA/Carina_inv.html.

Depth profiles of all CFCs for the Nordic Seas cruises are presented in Figs. 2-5 and relationships between CFC-11 and the other CFCs can be found in Figs. 6-8. These figures have served a valuable tool in the QC and will be referred to when appropriate. The cruise ID (EXPOCODE) is composed of the ships code and the starting date of the cruise and is given in Tables 1 and 2. More information of the EXPOCODES and the ships included in the Nordic Seas Carina can be found in Olsen et al. (2009).

\subsubsection{CFC partial pressure}

In addition to the concentration values, the CARINA data product also includes calculated partial pressures for the dissolved CFC (and for $\mathrm{CCl}_{4}$ ) samples; the pCFC data, expressed with units of pico $\left(10^{-12}\right)$ atmospheres or parts-pertrillion (ppt). The pCFC of a water sample is computed from the expression $\mathrm{pCFC}=\mathrm{C}_{\mathrm{SW}} / \mathrm{F}(\Theta, S)$ (Doney and Bullister, 1992), where $\mathrm{C}_{\mathrm{SW}}$ is the concentration (in pmol kg${ }^{-1}$ ) of the dissolved $\mathrm{CFC}$ in the seawater sample and $\mathrm{F}(\Theta, \mathrm{S})$ is the solubility of the $\mathrm{CFC}$ as a function of potential temperature and salinity (Warner and Weiss, 1985; Bu and Warner, 1995; Bullister and Wisegarver, 1998). This conversion of dissolved CFC concentrations to pCFCs removes the strong dependency on the CFC concentration on the temperature and salinity of the seawater sample and makes it possible to directly compare the levels of dissolved CFCs in the ocean with the equivalent equilibrium atmospheric partial pressures or atmospheric mixing ratios.

\subsection{Analysis approach}

As with the other parameters of CARINA, also the CFC data were subject to secondary quality control (QC). However, the transient behaviour of these compounds present some inherent problems with identifying and quantifying offsets in a straightforward way, as can be done for most of the other parameters. Therefore, a number of tools are used for the consistency control of the data and adjustments are recommended if there is consensus in the results from the different methods. For the quality evaluation of the Nordic Seas CFC data we used depth profiles of the CFCs, relationships between CFC-11 and the other CFCs and the surface saturations of the CFCs. The CFC data also underwent a consistency analysis using crossover and inversion approaches (Johnson et al., 2001; Tanhua et al., 2010), customised for the Nordic Seas (Olsen et al., 2009).

A useful tool for quality control of CFCs is the surface saturation, which is the ratio of the measured surface ( $<20$ dbar) concentration to the calculated equilibrium concentration of the CFC. The equilibrium concentration of a 

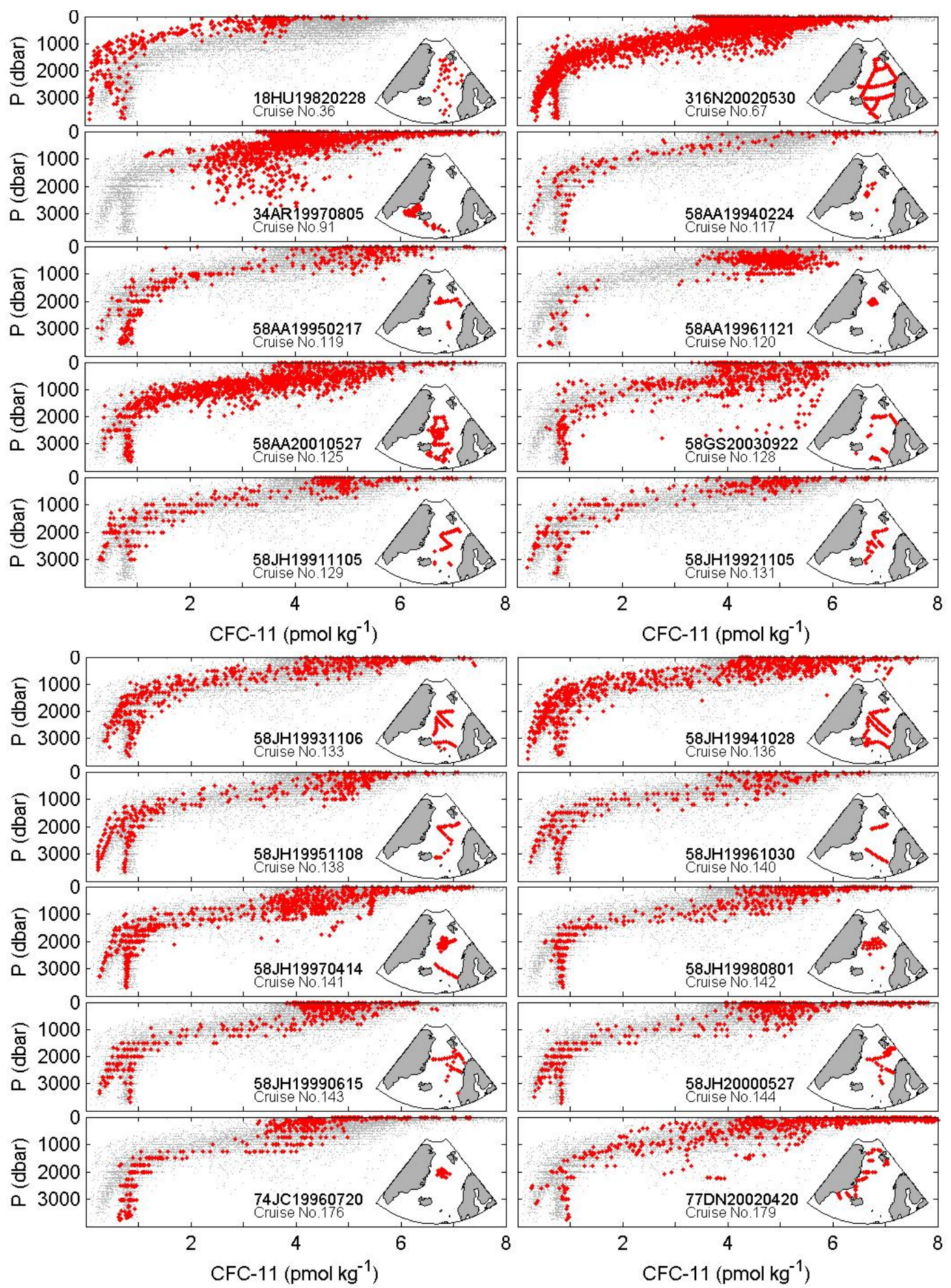

Figure 2. CFC-11 vs. pressure (dbar) for all Nordic Seas cruises in CARINA. The red dots mark data from each specific cruise, and the grey dots shows the CFC-11 data from all Nordic Seas CARINA cruises. The inserted map shows the specific cruise track.

CFC as a function of time is calculated from the solubility of the compound and the atmospheric history of the CFC (Walker et al., 2000; Bullister 2008, http://cdiac.ornl.gov/ oceans/new_atmCFC.html). In much of the surface layer of the world ocean the observed concentrations of dissolved
CFC-11 and CFC-12 are close to equilibrium with the overlying atmosphere. Consistently, most cruises in the Nordic Seas CARINA show surface saturations for CFC-11 and CFC-12 between 90 and $100 \%$ of equilibrium, with some clear exceptions (see Fig. 9). However, saturations in the 

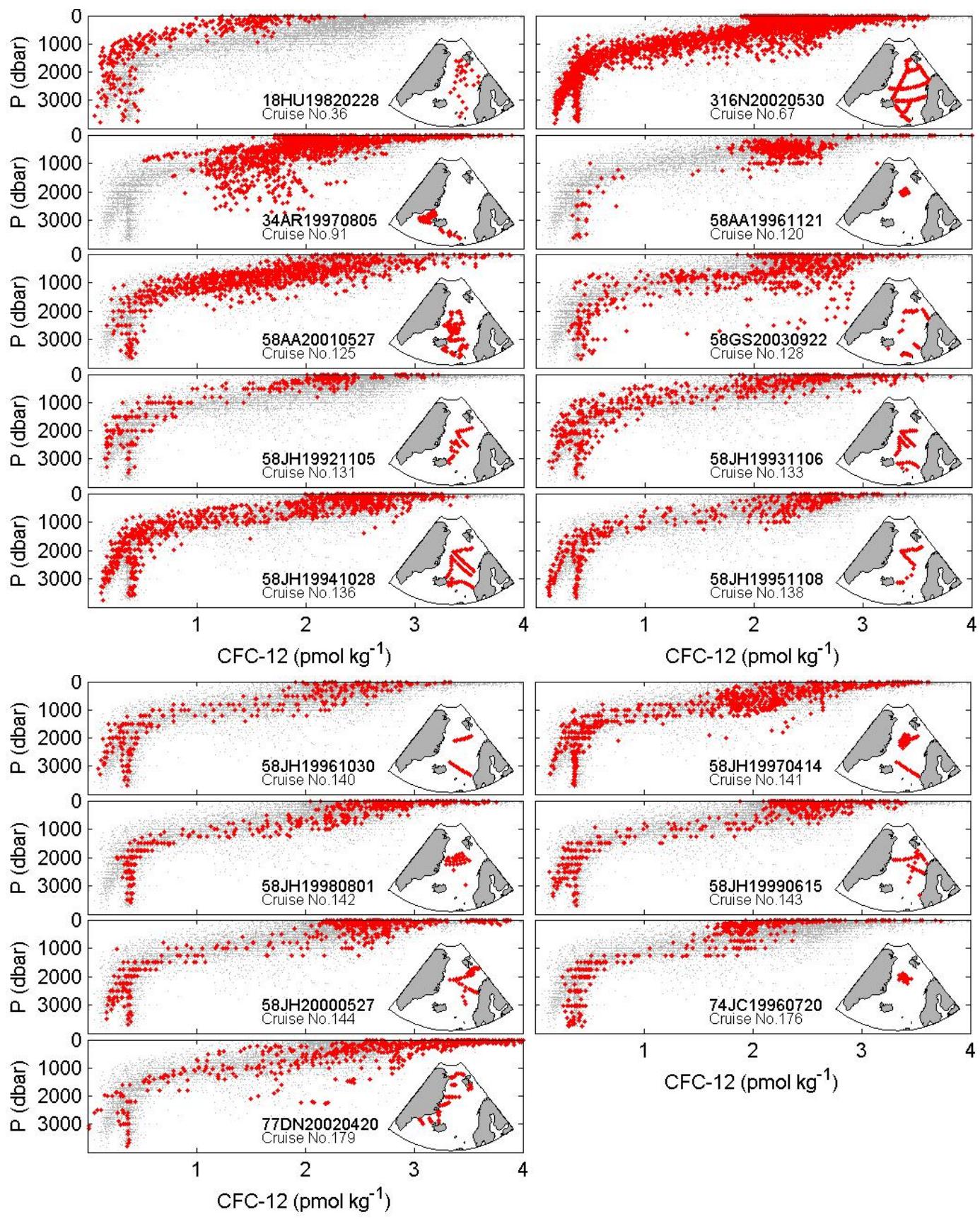

Figure 3. CFC-12 vs. pressure (dbar). See Fig. 2 for specifications.

surface waters of the Greenland Sea of $\sim 80 \%$ have been reported by several authors (Bullister and Weiss, 1983; Rhein, 1991; Anderson et al., 2000). This low saturation is generally considered to be a feature of deep-water formation regions where gas exchange rates are not rapid enough to bring the exceptionally deep winter mixed layers into equilibrium with the overlying atmosphere. Thus, low saturation levels do not prove that there is an offset in the data. Furthermore, the CFC saturations are possibly time-dependent in the
North Atlantic, with a lower degree of saturation prior to the 1990s when the atmospheric increase was faster (Tanhua et al., 2008), and this might also be expected for the Nordic Seas. CFC-113 and $\mathrm{CCl}_{4}$ have a slower gas transfer velocity than CFC-12, 20\% slower for CFC-113 (e.g., Roether et al., 2001) and $12 \%$ for $\mathrm{CCl}_{4}$ (Huhn et al., 2001), so in some circumstances a lower degree of saturation for these compounds might be expected. Another issue of importance is the nonstable behaviour of these two species in seawater (Huhn et 

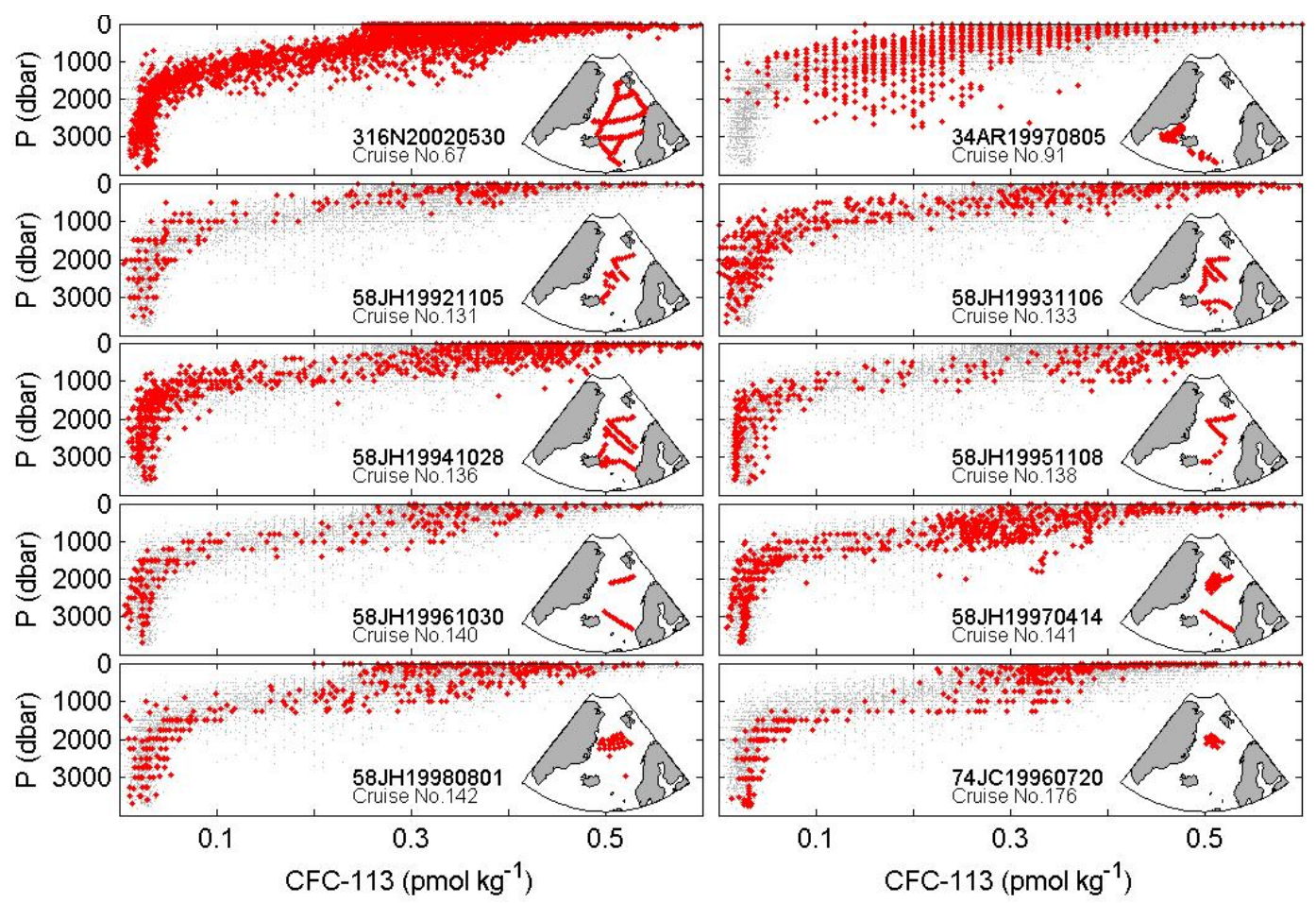

Figure 4. CFC-113 vs. pressure (dbar). See Fig. 2 for specifications.

al., 2001; Roether et al., 2001), which makes comparisons with the other CFCs more difficult. However, these nonstable behaviours appear to be in part temperature dependent, with more rapid removal rates in warmer water $\left(\geq 13^{\circ} \mathrm{C}\right)$. Since the surface waters of the Nordic Seas generally are significantly colder than $13^{\circ} \mathrm{C}$, average removal rates, although still significant, may be slower in the AMS than in some other regions.

From Fig. 9 it can be seen that the saturation of CFC-11 and CFC-12 in general follow each other very well, and the same is true for their uncertainty. They are also in agreement with the values for $\mathrm{CCl}_{4}$. CFC-113, on the other hand, frequently shows saturation as low as $70-80 \%$ (Fig. 9), consistent with the slower gas exchange and perhaps nonstable behaviour, and the variability of the saturation is larger. Some cruises deviate from the assumption that the saturation of CFC-11 and CFC-12 should be consistent to each other (Fig. 9). This will be taken into account when summarising the results from the different quality controls.

\subsection{Crossover and inversion}

In accordance with most of the CARINA data also the Nordic Seas CFCs underwent consistency evaluation with a crossover analysis, using the cnaX scripts described by Tanhua et al. (2010); with some minor modifications applied in the Nordic Seas (Olsen et al., 2009). The cnaX crossover routine defines crossover points from station pairs, from dif- ferent cruises, within $300 \mathrm{~km}$ from each other. Since two cruises can cross at several points, in different hydrographic regimes, each cruise pair's crossover stations were divided into groups of stations, or clusters; up to 6 clusters were defined, each within a circle of maximum radius of $175 \mathrm{~km}$. Profiles of the cruises in each cluster were interpolated using a piecewise cubic hermite interpolating approach, which minimizes extrapolation. The interpolated profiles of each cruise were then averaged and an offset and standard deviation profile for each cluster was calculated from data below 1900 dbar. From these profiles a weighted mean offset and weighted mean standard deviation were determined for each cruise pair and used for the inversion that calculated the corrections. The inversion method closely followed that of Johnson et al. (2001). They presented three models of different complexity to adjust a number of parameters and found that a model of intermediate complexity, the Weighted Least Square (WLSQ), showed the most satisfactory results. In the WLSQ model the standard deviation of each crossover is included in the calculation, but no a priori assumptions are made about the quality of the measurements. When this assumption is made a maximum allowed range of adjustments is set for each cruise, which tends to decrease the adjustments of individual cruises on cost of the overall performance. Models that do not include the uncertainty of the offset values are considered too simple (Johnson et al., 2001; Tanhua et al., 2010). 


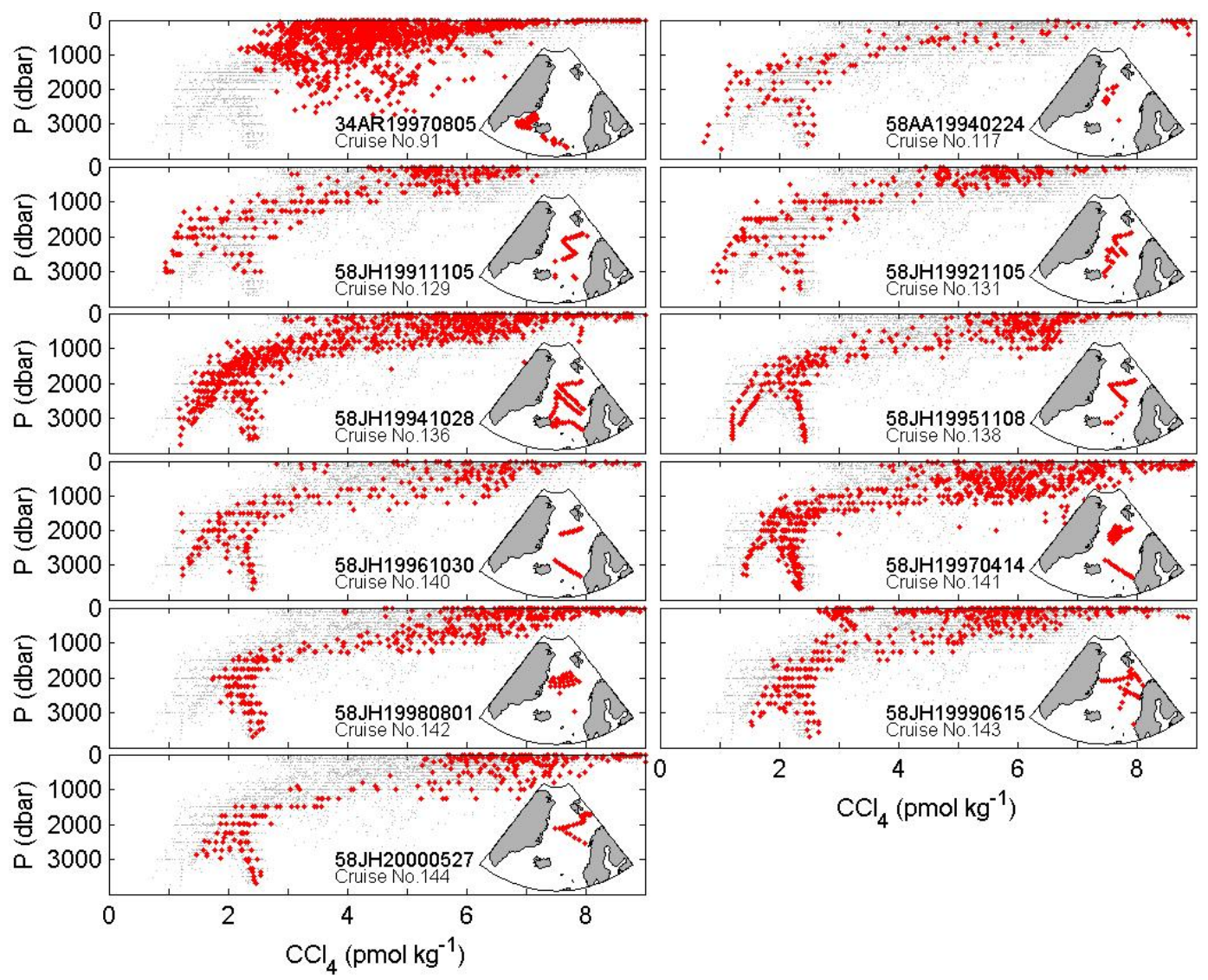

Figure 5. $\mathrm{CCl}_{4}$ vs. pressure (dbar). See Fig. 2 for specifications.

As mentioned in Sect. 3 the results can not be applied in a straight-forward way due to the transient nature of the CFCs, and the known transient behaviour of the Nordic Seas (e.g., Bullister and Weiss, 1983; Blindheim and Rey, 2004; Karstensen et al., 2005). The increase of the atmospheric CFC levels until, at least, the early 1990s (Walker et al., 2000) is likely to result in increased deep-water concentrations with time, and it is therefore very important to assess any offsets from the inversions together with the other tools used in the secondary QC; most importantly the surface saturation, but also depth profiles and ratios between the CFCs. The result of the crossover analysis is thus a tool to identify cruises where an offset is possibly present, which is then confirmed or rejected by other methods. For the crossovers in the Nordic Seas only data from depths below $1900 \mathrm{~m}$ have been used in order to minimize the effect of vertical mixing, which may result in higher CFC concentrations; deep convection in the Greenland Sea down to $1600 \mathrm{~m}$ have been reported in 2002 (Ronski and Budéus, 2005).

The results of the WLSQ inversion of cnaX crossovers are shown in Fig. 10, which shows the correction factors of the different CFCs that were suggested by the analyses. These suggestions will be viewed in the light of the previously described quality controls. The overall strategy is to compare the results from the inversions with the surface saturations. If any offset is found for both these indicators, and are consistent in direction and magnitude, an adjustment is recommended. The CFC ratios and depth profiles are also considered to support the decision.

The applied adjustments were never smaller than $\pm 5 \%$, or larger than $\pm 10 \%$. The lower limit was set to avoid adjusting biases that are either the result of natural variability or not significant in comparison to the precision of the measurements. The upper limit of adjustment was adopted both to minimise the risk of erroneously reducing differences due the transient behaviour of the CFCs, and also to be consistent with the saturation difference between CFC-11 and CFC-12, which did not exceed $10 \%$ for any cruise except one (58AA20010527).

\subsection{Adjusted cruise data sets}

Here we will discuss the cruises that have to be considered further after the different quality controls, and motivate any adjustments made to the data. As mentioned above any adjustment is based on the combined results of the crossover analyses and the surface saturations, but the CFC ratios and depth profiles are also taken into account. We have 

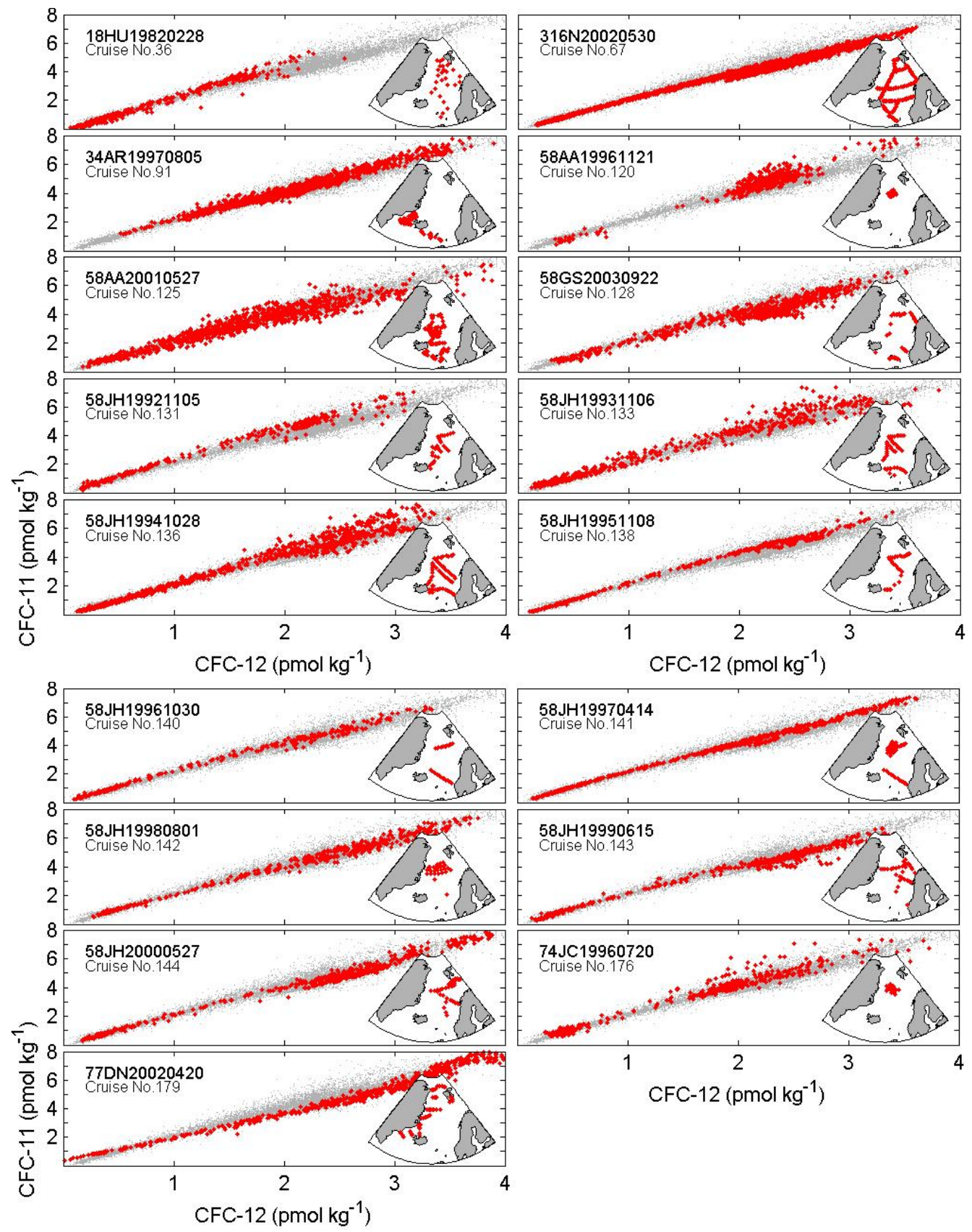

Figure 6. CFC-11 vs. CFC-12 for the Nordic Seas data. See Fig. 2 for specifications.

determined correction factors in steps of 5\% since the applied methods do not make a more accurate determination possible. This is consistent with the analyses of the North Atlantic CFCs (Steinfeldt et al., 2010). This is equivalent to stating that most data are accurate to within 5\%, and only obvious deviations from this could be unambiguously detected and adjusted. In contrary to the NA group we have, in some occasions, applied corrections also for $\mathrm{CFC}-113$ and $\mathrm{CCl}_{4}$. However, especially for CFC-113 this may be somewhat problematic due to analytical problems connected to this CFC; in some of the cruise data the surface saturations have been very high, which may have been caused by a contamination, or co-eluting chromatographic peak near CFC-113, while the surface saturation is very low at times, which could be due to unknown removal processes. Therefore we want to recommend caution with using the CFC-113 data, and make sure that these potential problems with this compound are appreciated. 

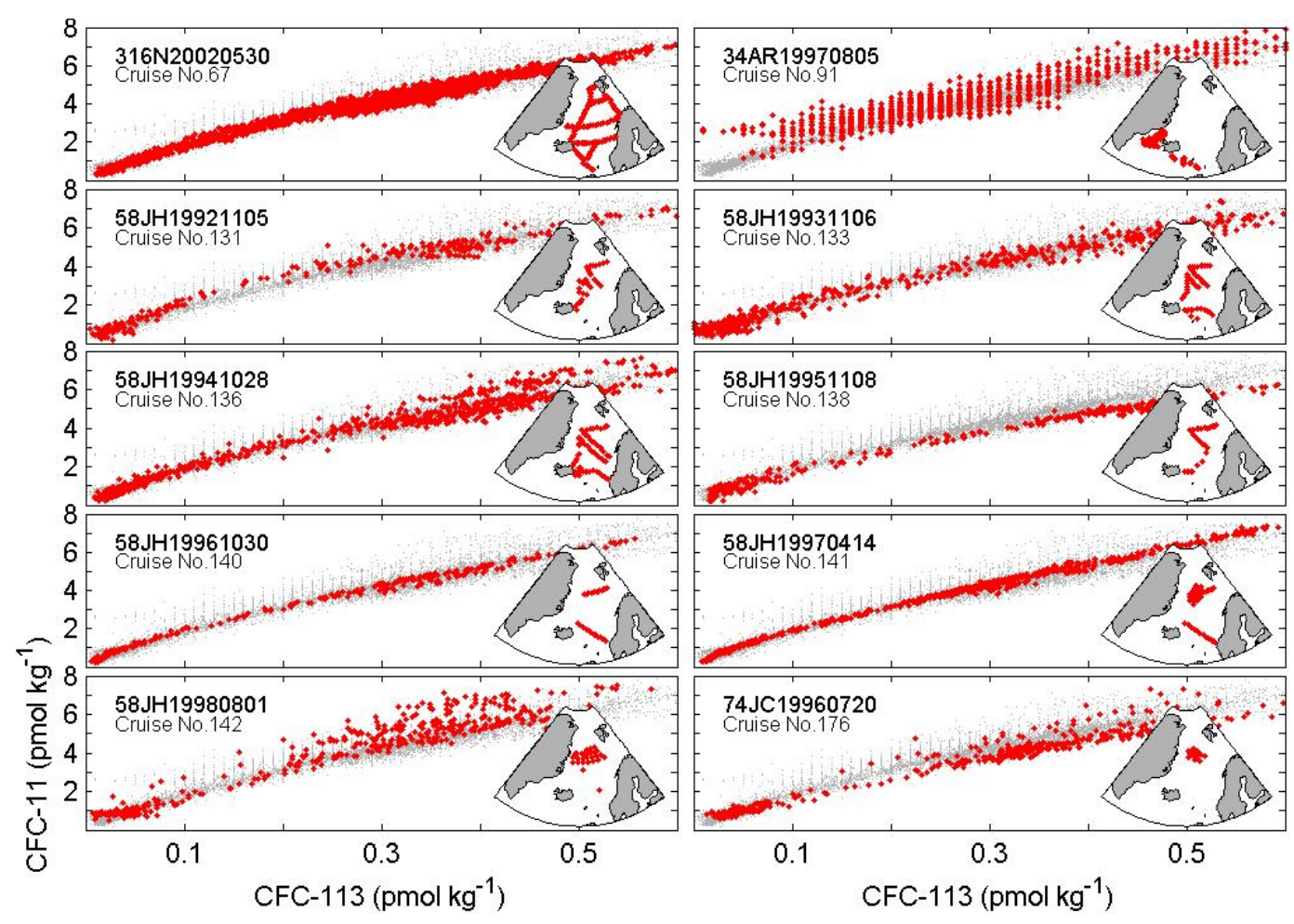

Figure 7. CFC-11 vs. CFC-113. See Fig. 2 for specifications.

In the following sub-sections (each header) we refer to the cruises by their respective EXPOCODES while the numbers in the parenthesis corresponds to the cruise numbers they have in the merged CARINA data file (see Table 1).

\subsubsection{HU19820228 (36)}

This 1982 cruise had a suggested correction factor of 1.25 for CFC-11, the largest offset of all cruises for CFC-11, and a suggested correction factor of $>1.1$ for CFC-12. However, since this is the oldest cruise in the dataset, these large offsets are not un-expected considering the transient nature of the CFCs and the rapidly increasing atmospheric levels of CFCs at the time of the cruise. The saturation of CFC-11 was in the order of 5\% higher than for CFC-12, and taking this together we applied an adjustment of 1.05 to the CFC-11 data. This will make the CFC-11 and CFC-12 more consistent, but will keep the clear difference between these data, collected a decade earlier during late winter, and the rest of the cruise data sets.

\subsubsection{N20020530 (67)}

While near-surface CFC-11 and CFC-12 samples were fully saturated, the surface saturation of $\mathrm{CFC}-113$ was the highest of all cruises. In qualitative accordance with this, the inversion suggested a correction of 0.80 , but we applied a more modest adjustment of 0.9. Possibly the correction could have been larger based on the surface saturation, however, due to the potential problems with this CFC (see above) we prefer to be more careful when applying a correction of CFC-113 data. As stated above caution is advised for the usage of these data.

\subsubsection{AR19970805 (91)}

This cruise sampled the Greenland-Scotland Ridge, and displayed a wider spread in the data vs. pressure (Figs. 2-5) due to the complex hydrography in the area, but still a tight relationship between CFC-11 and CFC-12 (Fig. 6). Nevertheless, due to the limited overlap with other cruises in the Nordic Seas we did not consider this cruise for adjustments. However, the saturation of CFC-11 is very high and almost $10 \%$ higher than for CFC-12 and the North Atlantic group recommended a correction factor of 0.95 of the CFC-11 data (Steinfeldt et al., 2010). Since this will decrease the saturation difference the CFC-11 data have been adjusted according to this.

\subsubsection{AA19940224 (117)}

The inversion gave a strong offset for CFC-12 in these data, with a suggested correction factor of 0.3 . However, this offset cannot be adjusted by a single correction factor; especially since the surface saturations implies that the CFC-12 values might be only $5 \%$ too high. Nevertheless, since the offset 


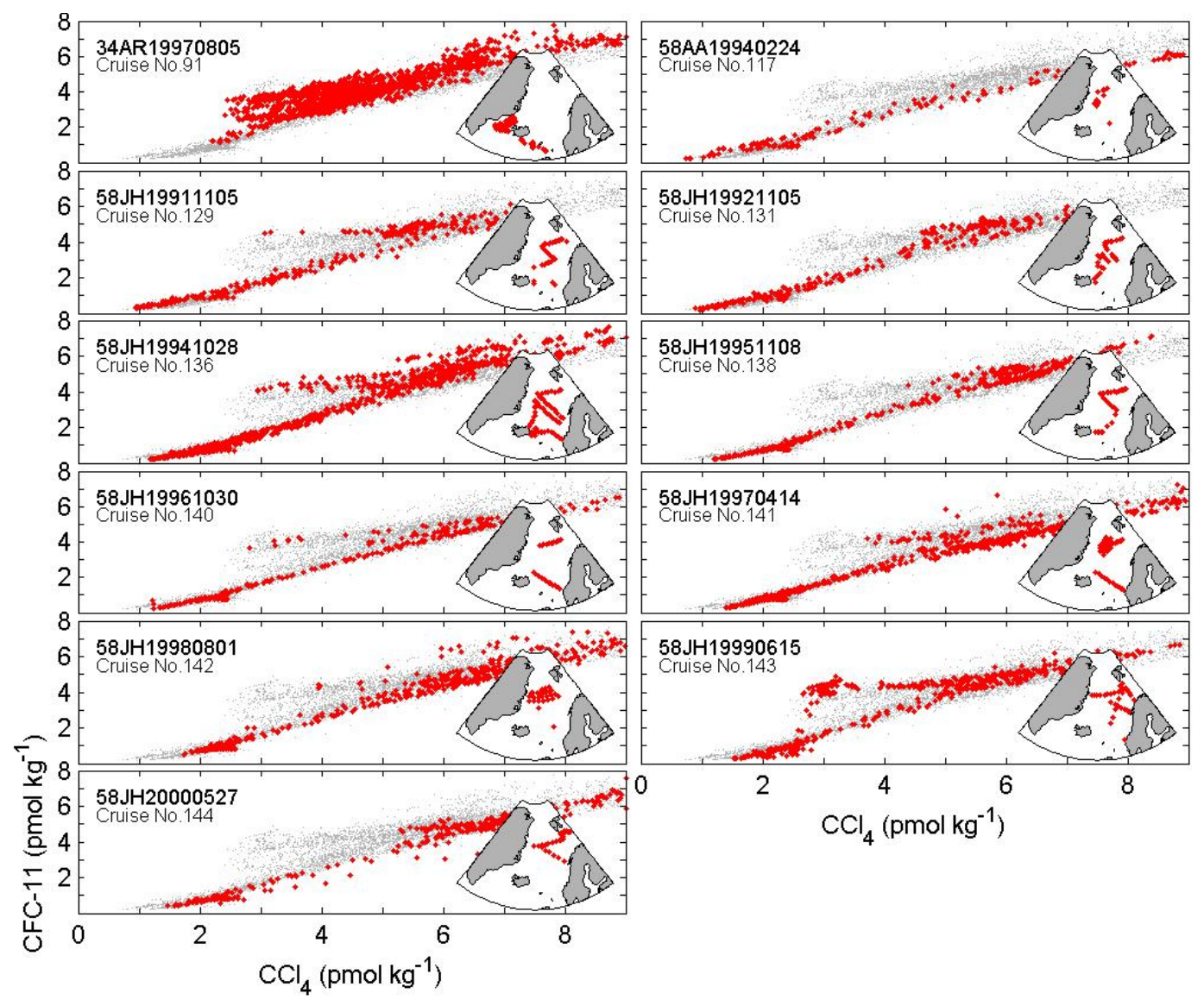

Figure 8. CFC-11 vs. $\mathrm{CCl}_{4}$. See Fig. 2 for specifications.

implied from the inversion is too large to account for and inconsistent with the surface saturation, we flagged the CFC12 data as questionable, which excluded these data in the final CARINA data product.

The results of the WLSQ inversions of the cnaX crossovers also implied that the $\mathrm{CCl}_{4}$ is too high, and should be lowered by $10 \%$. This is supported by the mean surface saturation that is $115 \%$, and we thus adjusted the data with a factor of 0.9 .

\subsubsection{AA19950217 (119)}

There was a very large offset suggested for CFC-113 from the inversion, and at the same time the surface saturation was the lowest seen for any of the cruises, for all measured CFCs, with rather large uncertainties (Fig. 9). The spread in the CFC-12 data was larger than for any of the other Nordic Seas cruises (not shown) and based on these results we flagged the CFC-12 and CFC-113 data as questionable and thus not used in the final data product. As mentioned above also CFC11 showed a low saturation with quite large scatter in the surface values. However, this can be expected for a winter cruise in the Greenland Sea, with a deep mixed layer, and can not alone motivate an adjustment. The inversion suggested a correction factor of 1.1 for the CFC-11 data, which would put the surface saturation in level with most of the Nordic Seas cruises. The adjustment also makes the deep-water values consistent with the values from the time-adjacent cruises (see Fig. 10), which justifies the correction.

\subsubsection{AA20010527 (125)}

There was clearly an issue with the more shallow CFC-12 data for this cruise. The surface saturation was $\sim 120 \%$, and showed large uncertainty, while CFC-11 was only slightly oversaturated. The depth profiles and the CFC relationship indicate that it is the data from the upper parts of the water column that are a problem. Due to this a careful re-check of the CFC-12 data was performed, resulting in recommendations to flag a rather large amount of the surface samples as questionable. The inversion suggested that the CFC-12 data was $7 \%$ too high and we applied an adjustment factor of 0.95 . 

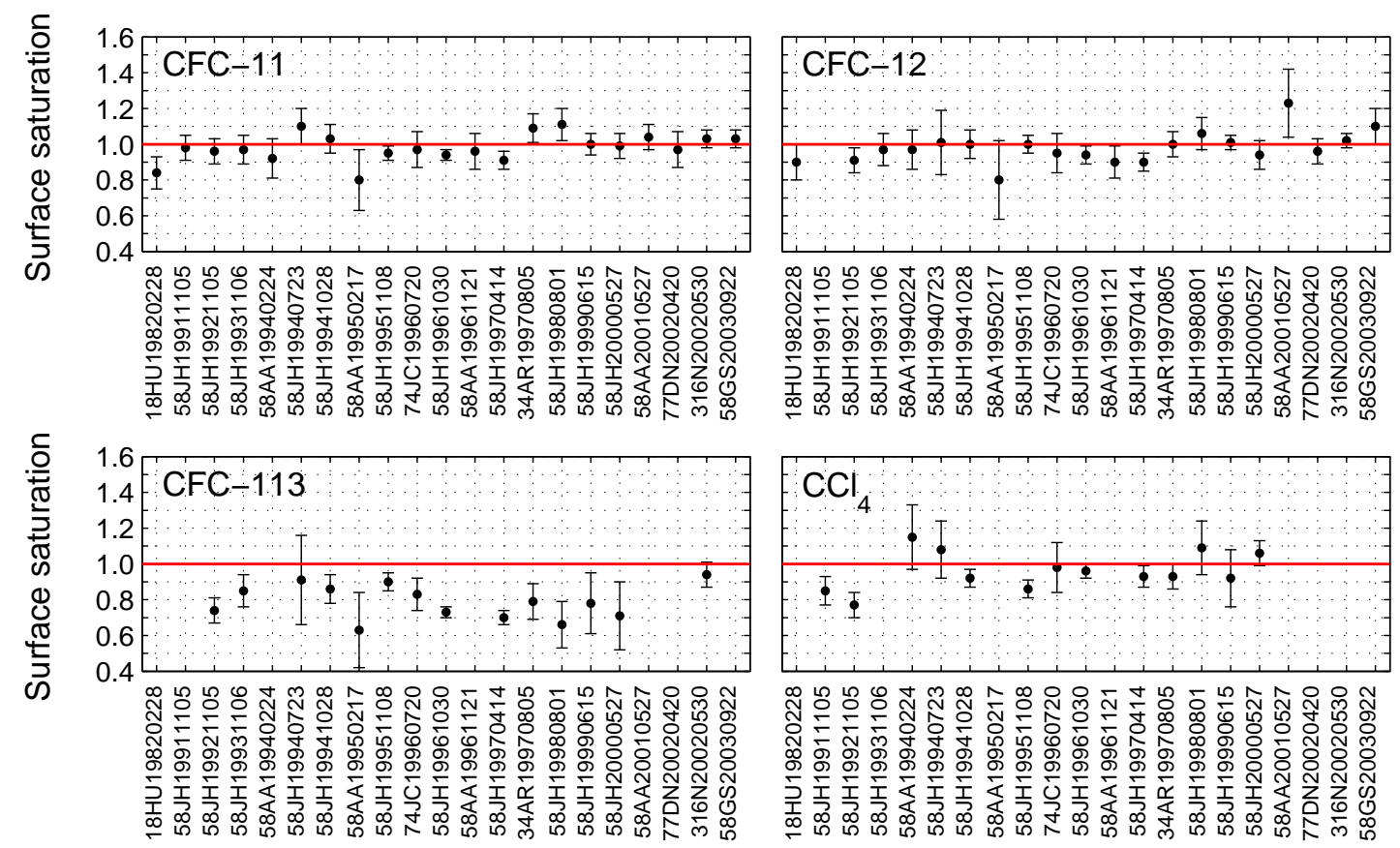

Figure 9. Surface saturations (upper 20 dbars) of the CFCs in the Nordic Seas cruises of CARINA. The error bars show the standard deviations. The cruises are sorted chronologically in order to see any trends in the data.
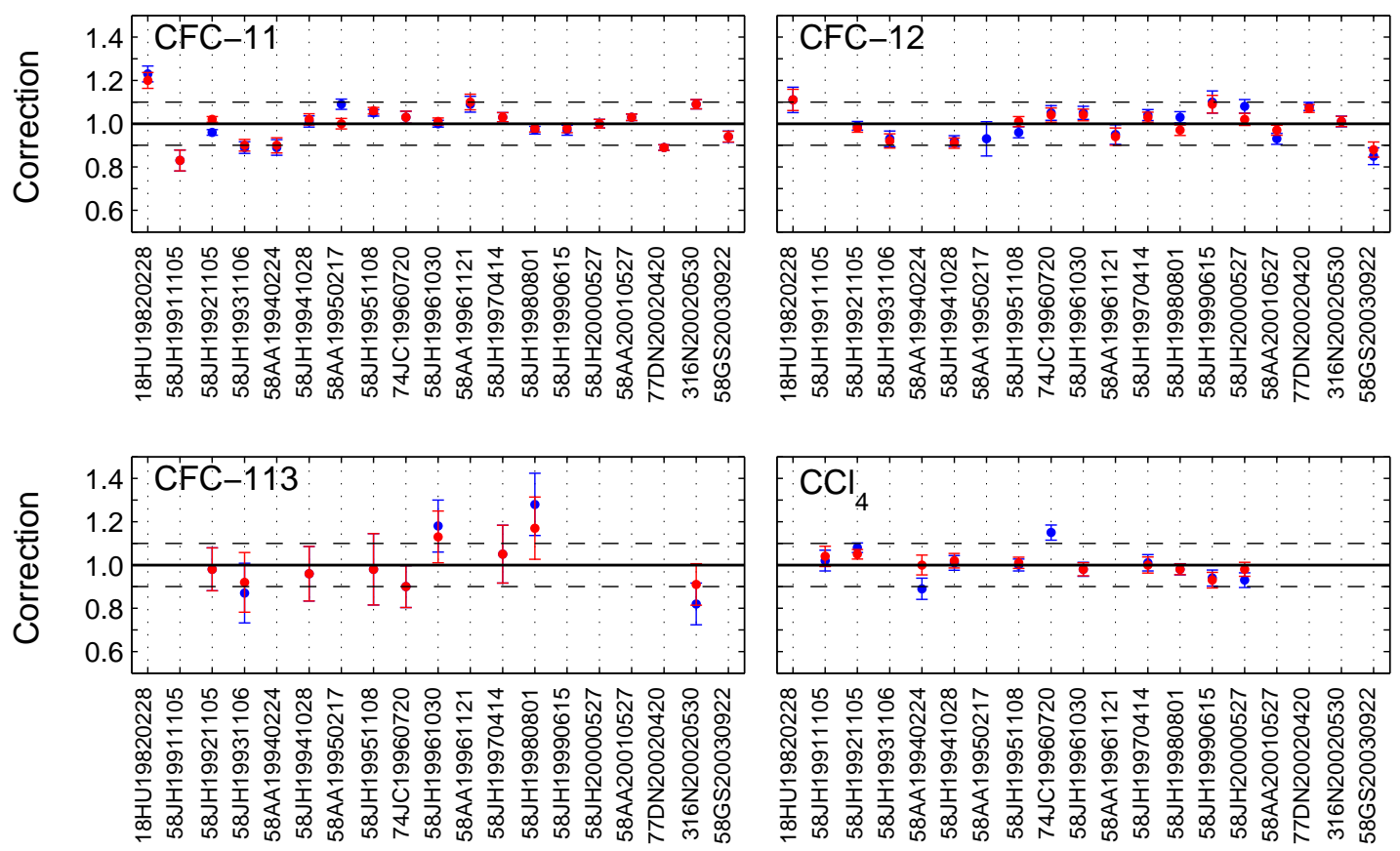

Figure 10. Suggested correction factors (and their standard deviations) of the CFCs from the cnaX inversions of the crossover analyses of the Nordic Seas data. The blue and red dots show the results before and after the adjustments were applied, respectively. 58JH19940723 and 34AR19970805 were not included in the final inversions for any of the CFCs. The cruises are sorted chronologically in order to see any trends in the data. 


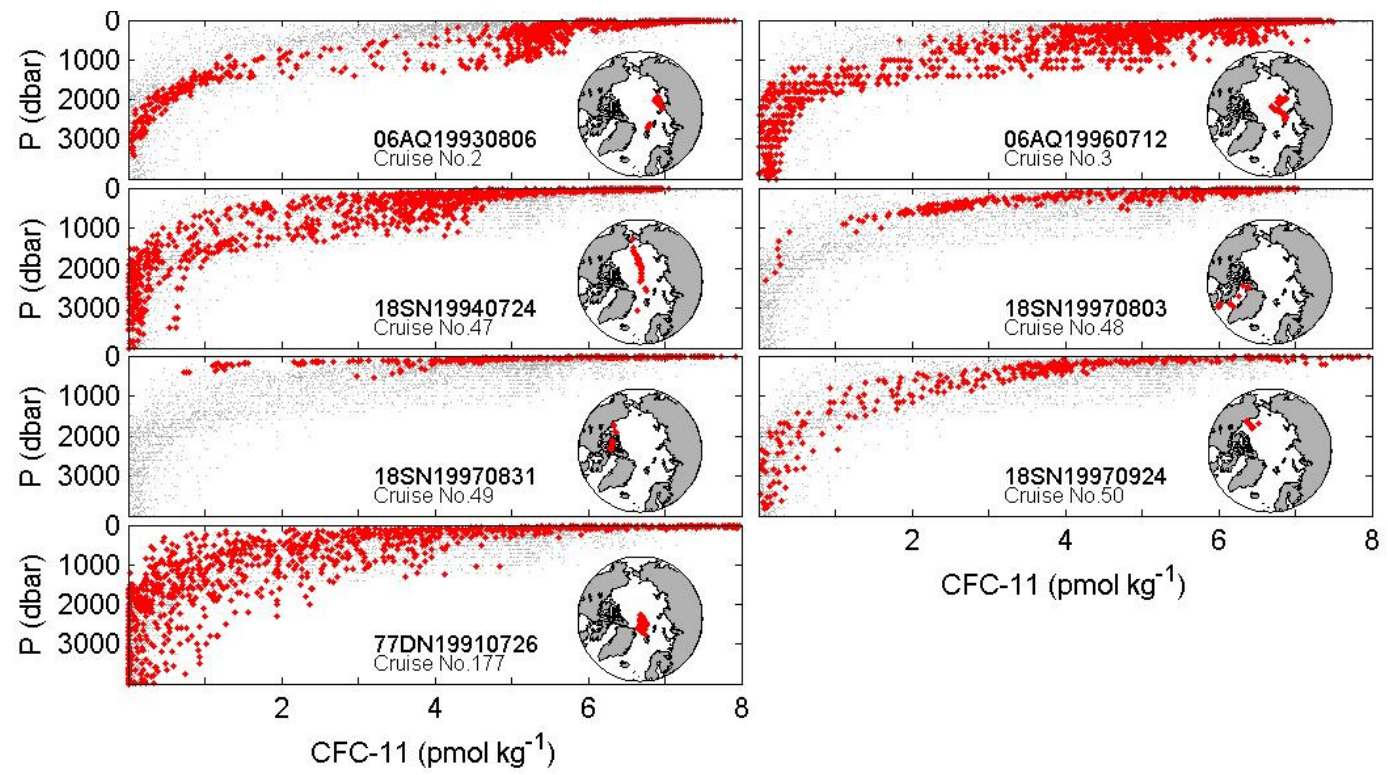

Figure 11. CFC-11 vs. pressure (dbar) for all Arctic Ocean cruises in CARINA. The red dots mark the data from each specific cruise, and the grey dots shows the CFC-11 data from all Arctic Ocean CARINA cruises. The inserted map shows the specific cruise track.

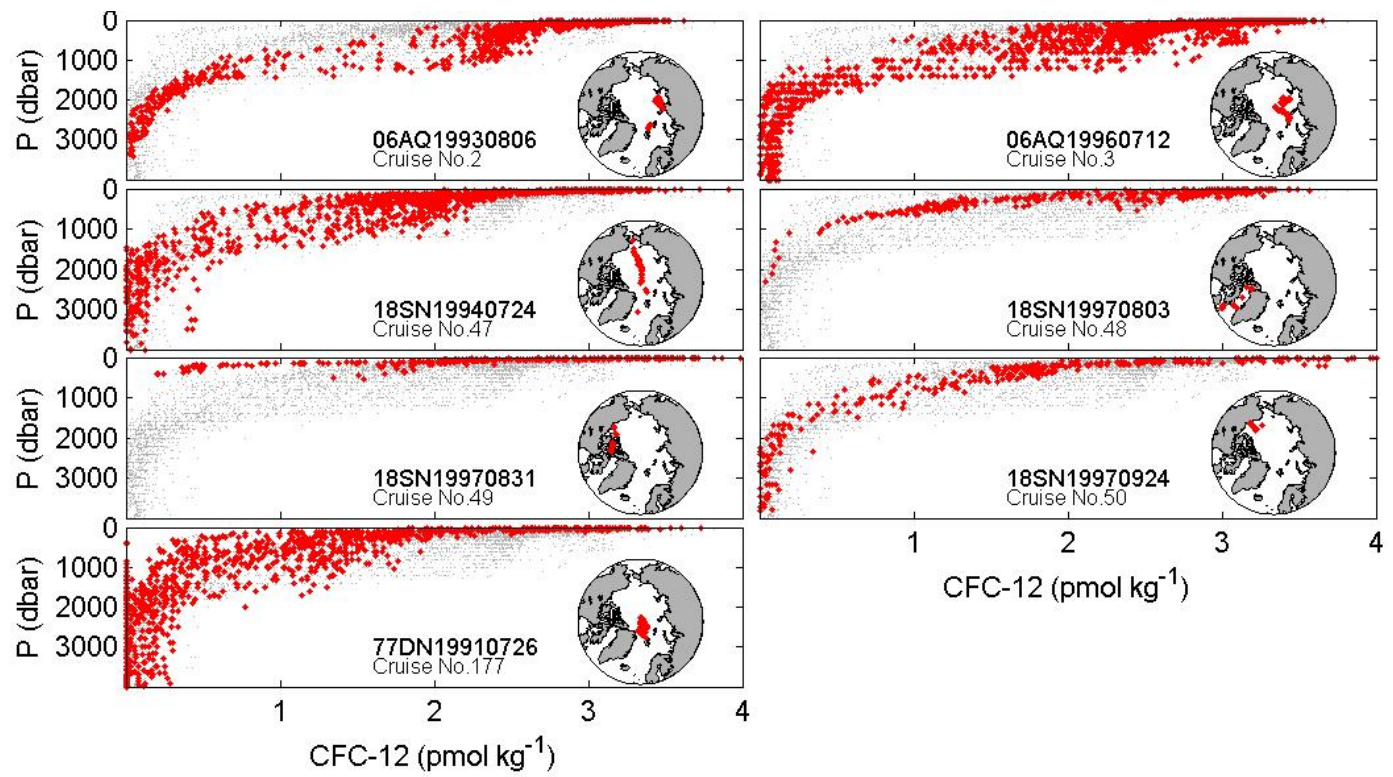

Figure 12. CFC-12. See Fig. 11 for specifications.

\subsubsection{GS20030922 (128)}

The surface saturation was between 5 and $10 \%$ higher for CFC-12 than for CFC-11, and this is somewhat supported by the inversions, suggesting a correction factor of 0.85 for CFC-12, and a smaller one of 0.94 for CFC-11. Obviously, both CFCs cannot be adjusted since that would keep the difference in surface saturations constant. An adjustment factor of 0.95 is applied to the CFC-12 data.

\subsubsection{JH19911105 (129)}

The WLSQ inversion implied that the CFC-11 values from this cruise were too high and suggested a downward correction of almost $20 \%$. The $\mathrm{CCl}_{4}$ values were, on the other hand, suggested to have an offset of only $5 \%$. The surface saturations were close to $100 \%$ for CFC- 11 and $\sim 85 \%$ for $\mathrm{CCl}_{4}$. Unfortunately no CFC-12 data are available for this cruise, making any judgment of the CFC-11 values more difficult. However, the offset in the deep water, seen from the 

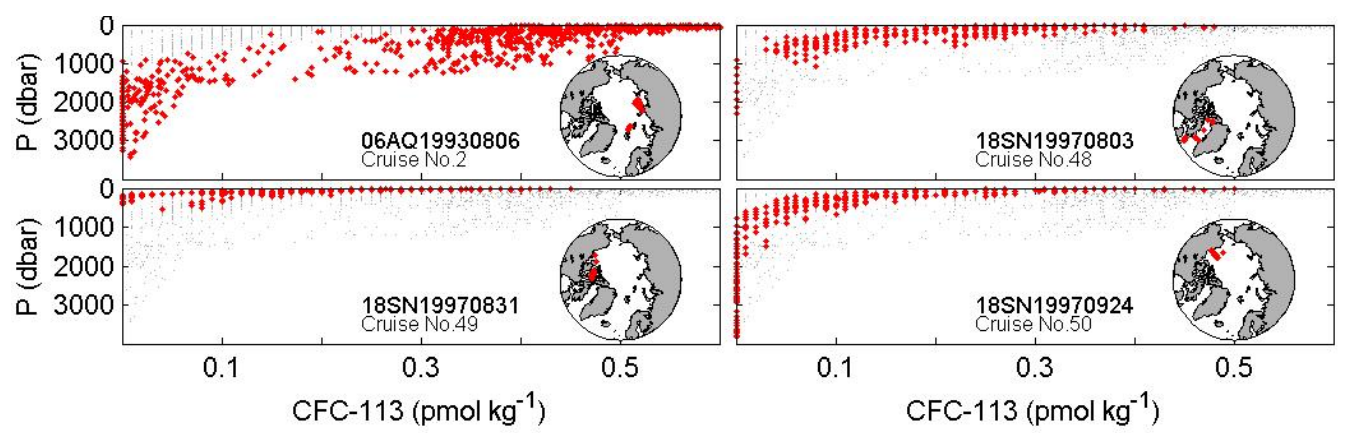

Figure 13. CFC-113. See Fig. 11 for specifications.

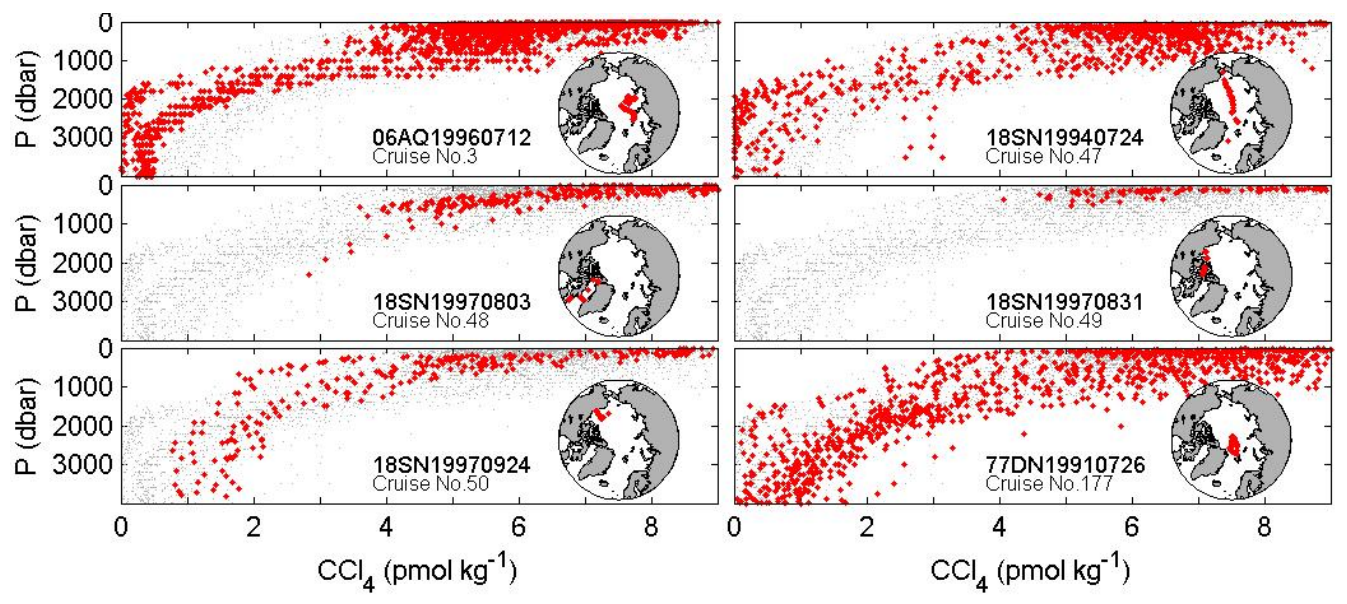

Figure 14. $\mathrm{CCl}_{4}$. See Fig. 11 for specifications.

inversion, is not supported by the surface saturation, where the latter agrees with the saturation of the cruises the few years after 1991. Thus, no adjustment is recommended for CFC-11. We also left $\mathrm{CCl}_{4}$ without any adjustment, but this is a less certain case since the inversion and the surface saturation actually support each other. Nevertheless, when comparing the surface saturation in the 1992 cruise (see Sect. 5.9) with this 1991 cruise the former should be adjusted in order to reach a higher consistency. Due to this we decided to be somewhat cautious and leave the 1991 as they are.

\subsubsection{JH19921105 (131)}

There was a 5\% saturation difference between CFC-11 and CFC-12, with the former being higher, but the inversions did not suggest any clear correction, but indicated that the CFC11 data are slightly too high. Since this is consistent with the difference in surface saturation we applied a correction factor of 0.95 of the CFC-11 data. The WLSQ inversions suggested a correction factor for $\mathrm{CCl}_{4}$ of 1.1. The surface saturation of $\mathrm{CCl}_{4}$ in these data was the lowest of all cruises in the Nordic Seas $(<80 \%)$. Since both the low saturation and the suggested correction from the inversion support an increase of the $\mathrm{CCl}_{4}$ values we applied an adjustment of 1.05 .

\subsubsection{JH19931106 (133)}

The result from the cnaX WLSQ inversion suggests that the CFC-113 data are almost $20 \%$ too high. The surface saturation for $\mathrm{CFC}-113$ was $85 \%$ during the cruise, while both CFC-11 and CFC-12 showed full saturation. The CFC-113 saturation is approximately $5 \%$ higher than the general mean for CFC-113, and we adjusted the CFC-113 data with a correction factor of 0.95 .

\subsubsection{JH19940723 (135)}

The inversions identified large offsets for CFC-11 and CFC12 for this cruise (not shown), and the saturations were generally high with large uncertainties (Fig. 9). However, most of the stations were located in, or in the vicinity of, the overflow regions along the Greenland-Scotland Ridge, so a larger spread of the data could be expected. Nevertheless, the quality of the data is questionable and the data will be flagged as poor and not be included in the merged data file; this was also found by the North Atlantic group (Steinfeldt, et al., 2010). 


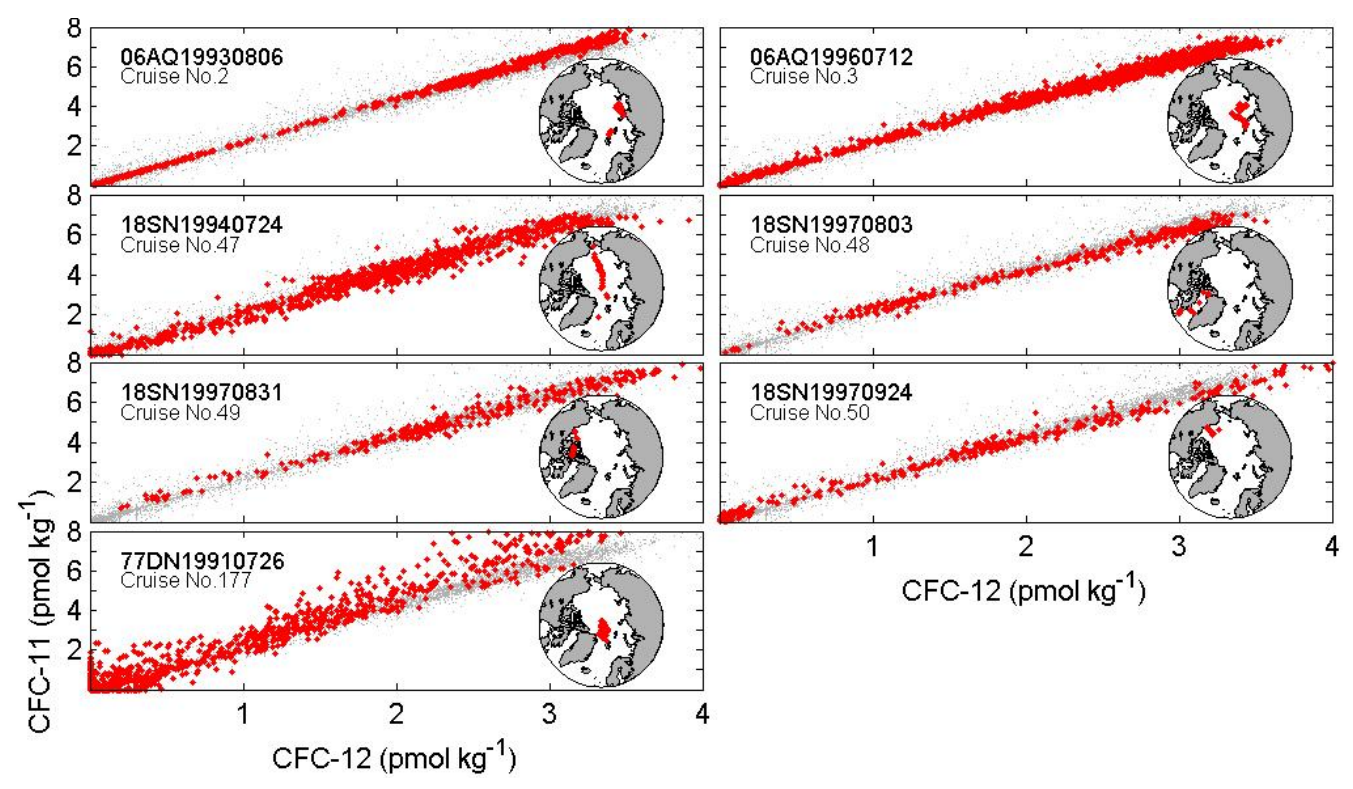

Figure 15. CFC-11 vs. CFC-12 for the Arctic Ocean data. See Fig. 11 for specifications.
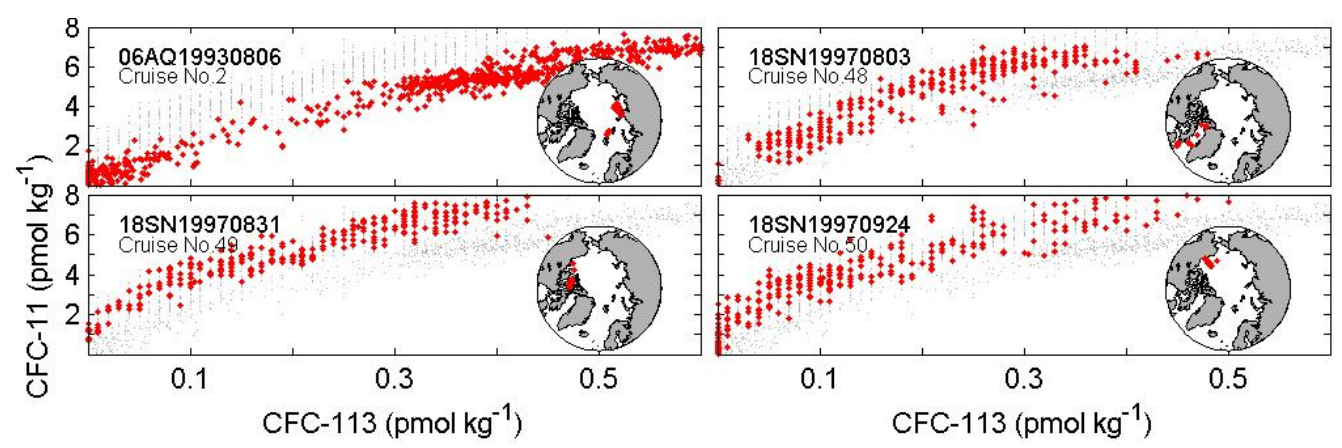

Figure 16. CFC-11 vs. CFC-113. See Fig. 11 for specifications.

\subsubsection{JH19951108 (138)}

The surface saturation was 5\% higher for CFC-12 than for CFC-11, with low uncertainty in both values. The inversion suggested a rather small upward correction of CFC-11 and an even smaller downward correction of CFC-12. Due to the fact that the inversion and the saturation difference point in the same direction we apply a 0.95 adjustment of the CFC- 12 data.

\subsubsection{JH19961030 (140)}

The surface saturation of CFC-113 was in the order of $70 \%$, lower than for the other CFCs (Fig. 9). The inversion suggested a correction factor of 1.2 , which is too high as compared to the saturation value, but we adjusted the data with 1.05 .

\subsubsection{JH19980801 (142)}

There were some differences in surface saturations in these data (Fig. 9), with CFC-11 and $\mathrm{CCl}_{4}$ being supersaturated by $10 \%$ and $\mathrm{CFC}-12$ with $5 \%$. CFC-113 on the other hand displayed one of the lowest surface saturations of all Nordic Seas data $(<70 \%)$. The inversions suggested small corrections for CFC-11 and CFC-12, downward for the former and upward for the latter. Since the $\mathrm{CCl}_{4}$ saturation is as high as for CFC-11, and received no suggested offset from the WLSQ inversion, we adjusted the CFC-12 data with 1.05 , which will make these three CFCs consistent. The situation for CFC-113 is different though. The inversion suggested that the data are too low, in agreement with the low saturation values, and that the correction factor should be 1.25 . We follow the direction of this correction and applied an adjustment factor of 1.1, which is our upper limit of adjustment to tracer data. 

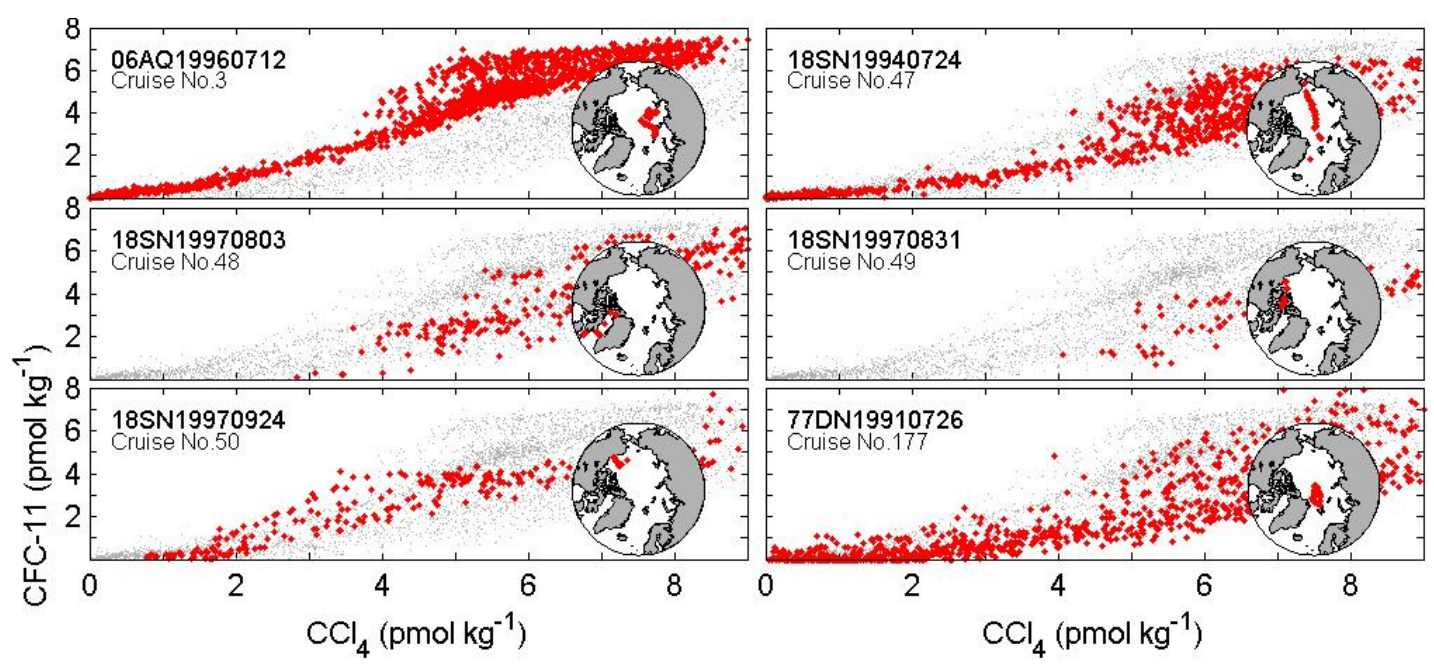

Figure 17. CFC-11 vs. $\mathrm{CCl}_{4}$. See Fig. 11 for specifications.
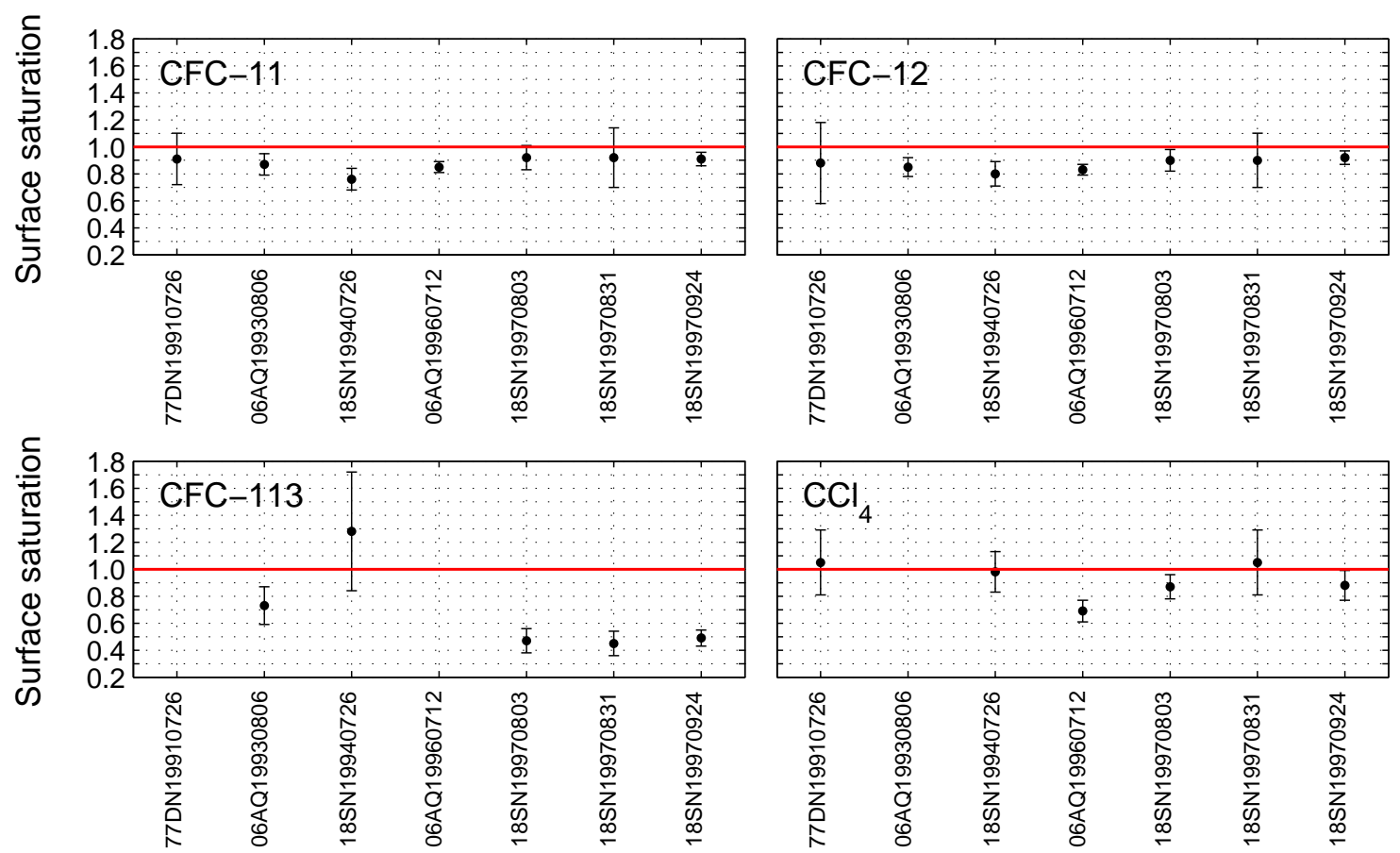

Figure 18. Surface saturations (upper 20 dbars) of the CFCs in the Arctic Ocean cruises of CARINA. The error bars show the standard deviations. The cruises are sorted chronologically in order to see any trends in the data.

\subsubsection{JH19990615 (143)}

The inversion indicated a very large offset for CFC-113 and suggested a correction factor of 2.3. This is too high to give reliable data, especially since the surface saturation equalled the mean saturation of all CFC-113 cruise data, even if the uncertainty was relatively high. Based on this the CFC-113 data are flagged as questionable and not included in the final data product.

\subsubsection{JH20000527 (144)}

No consistency was seen in the surface saturations, where $\mathrm{CFC}-11$ was equilibrated, and $\mathrm{CFC}-12$ and $\mathrm{CCl}_{4}$ was undersaturated and oversaturated, respectively. These differences are supported by the inversions that suggest correction factors of 1.05 and 0.95 , for $\mathrm{CFC}-12$ and $\mathrm{CCl}_{4}$, respectively. Since these two controls are consistent we followed the recommendations from the inversions for $\mathrm{CFC}-12$ and $\mathrm{CCl}_{4}$ 
(Fig. 10). CFC-113 was clearly undersaturated ( 70\%), with quite high uncertainty, but the inversion suggested a large offset and correction of $>1.5$ and we flagged the CFC-113 data as questionable.

\subsubsection{JC19960720 (176)}

The surface saturation was consistent for all CFCs and did not deviate from the overall mean for the Nordic Seas cruises; slightly below full saturation for all except CFC-113 that showed a saturation of $80 \%$. The inversion only found a clear offset for $\mathrm{CCl}_{4}$, and suggested that these data should be increased by $15 \%$. However, the fact that this deviation was not observed in the surface saturation, led us to flag the $\mathrm{CCl}_{4}$ data as questionable, and hence to exclude them from the final data product. The other CFCs are included without any recommended adjustments.

\subsubsection{DN20020420 (179)}

All CFCs were sampled during this cruise, but there were some analytical problems with the CFC-113 and the $\mathrm{CCl}_{4}$ data, giving data of too low quality. As a result, these data were flagged as questionable (by R. Key) in an earlier stage of the quality assessment and are thus not included in the CARINA data set.

\subsection{Consistency Test of Final Nordic Seas CFC Data}

An evaluation of the consistency of the final Nordic Seas CFC data was performed with a cnaX crossover analysis (Tanhua et al., 2010) of the data, after the recommended adjustments had been applied. The corrections suggested by the WLSQ are shown in Fig. 10. As can be seen the adjusted data did not show offsets larger than $\pm 10 \%$ (depicted by the dashed lines), except a few exceptions (mentioned above). No trend could be seen in the CFC-11 or CFC-12 data. CFC113 and $\mathrm{CCl}_{4}$, on the other hand, show some indications of this; CFC-113 seem to be decreasing up to the end of the 1990s (even if this might not be statistically significant due to the large variability) and then clearly higher values in 2003 (58GS20030922), while $\mathrm{CCl}_{4}$ shows an increasing trend during the 1990s, which might be somewhat surprising.

\subsection{Arctic Ocean CFC data}

The secondary QC of the Arctic Ocean cruises in CARINA was treated separated from the Nordic Seas cruises. The main reason is that the Arctic Ocean and the Nordic Seas are two hydrographically different regions; the ice conditions affect the surface saturations of the CFCs, and the deep waters of the Arctic Ocean are less homogeneous than those in the Nordic Seas. Thus, differences revealed by comparing data from these two areas may both be confused with regional characteristics, and hide actual offsets in the data. Moreover, due to the many difficulties connected to surveys in the Arctic Ocean the sampling cover of this area is much sparser than in the Nordic Seas, and thus crossover analysis are less suitable for these data.

An overview of the Arctic Ocean CFC data included in CARINA can be found in Table 2, and the geographical location of the stations in Fig. 1. The description of the other Arctic Ocean cruises, 26 in total, and all other sampled parameters can be found in Jutterström et al. (2010). The collection of CFC data contains five cruises, where the most recent one, in 1997, has been divided in three parts. Due to the sparse number of cruises, often covering different parts of the Arctic Ocean, only one crossover was found, and this suggested only a small offset. The second QC did instead follow most of the initial steps of the procedure used for the Nordic Seas data, including a careful check of the depth profiles, $\mathrm{CFC}$ ratios and surface saturations. The CFC profiles and relationships are shown in Figs. 11-17.

The analytical method is the same as for the Nordic Seas data; see Sect. 2.

\subsection{Individual cruise assessments of the Arctic Ocean data}

From the profiles and the relationships, most of the CFC data from these cruises seem to be of good quality, with a few exceptions. The earliest cruise, with the Swedish icebreaker Oden in 1991 (77DN19910726; \#177) showed a large spread (Figs. 11-12, 14-15, 17), and the metadata also stated that there were some problems with the general precision. Therefore these data were carefully re-checked, resulting in the recommendation to flag a substantial amount of values as questionable, especially for CFC-11. 18SN19940724 (47) had some problem with the CFC-113 data, showing a large scatter, and these are now flagged questionable.

As for the Nordic Seas data, the surface saturations were used as a quality control tool. The calculated values and their uncertainties are shown in Fig. 18. The overall means, and their standard deviations were, for CFC-11 $0.88 \pm 0.06$; CFC$120.87 \pm 0.04$; CFC- $1130.68 \pm 0.35$; and $\mathrm{CCl}_{4} 0.92 \pm 0.14$. The saturations of CFC-11 and CFC-12 were stable, seen from the low uncertainty among all data. They were also consistent with each other; throughout the collection their relationship differed less than 2\%, except for 1991 and the 1994 cruises. The large spread in the 1991 data, and the amount of reflagging now recommended for this cruise, makes it almost impossible to suggest any reasonable adjustment. The 1994 data is better, though, but the difference in saturation between the different CFCs is larger.

The saturation of CFC-113 is not as constant, however, seen from the very large uncertainty. When looking at the different cruises (Fig. 18), 18SN19940724 stands out with a very high degree of supersaturation, but as mentioned previously this cruise has a very large spread. When omitting 
these data the mean of the CFC-113 saturation is $0.54 \pm 0.13$. This is very low, obviously, but it is hard to evaluate how reasonable this number is.

The saturation of $\mathrm{CCl}_{4}$ has been very variable, as seen in Fig. 18; from a slight supersaturation with a large spread (77DN19910726 and 18SN19970831), to a clear undersaturation with a small scatter (06AQ19960712).

\subsection{Recommendations for the Arctic Ocean data}

With only one crossover available it is clearly more difficult to assess any adjustments to the data. Nevertheless, the secondary QC identified some issues and some differences in the data that can support some adjustments. Most of the recommendations for the Arctic Ocean data were on reflagging samples as questionable, and hence exclude some data from the final data product. The motivation for this was to obtain as many reliable cruise data sets as possible. This is especially true for the 77DN19910726 cruise, which, as mentioned above, showed a generally larger spread in all CFCs compared to the other Arctic Ocean cruises (see Figs. 11, 14, 15, 17). However, except for the rather large amount of recommended reflagging no other adjustments are suggested for this cruise.

The very low surface saturation of $\mathrm{CCl}_{4}$ in the 06AQ19960712 cruise (Fig. 18) might indicate that the data should be corrected, and this is somewhat supported by the relatively low mean in the deep water. However, the magnitude of such an adjustment is almost impossible to assess, and we will therefore leave these data without changes.

\subsubsection{SN19940724 (47)}

This was the only cruise that received any adjustments. Those were based on the difference in surface saturation between CFC-11 and CFC-12, where the former was $4 \%$ lower, and both showed low uncertainty. For all other cruises the saturations are consistent, or with a somewhat higher saturation for CFC-11. Moreover, when comparing the CFC11/CFC-12 relationship among all cruises (see Fig. 15) the 1994 data does seem a bit too high in CFC-12 relative to CFC-11. In addition, the deep-water mean for this cruise is actually the lowest of all the Arctic cruises, which would then support an upward adjustment of the data. Therefore, we applied an adjustment of CFC-11 with 1.05 .

CFC-113 was supersaturated with $\sim 30 \%$, with a very large uncertainty. In addition the data were very noisy (not shown). Together this suggests that the precision of the CFC-113 data is rather poor and we flagged them as questionable.

Acknowledgements. We would like to acknowledge all the tremendous work by different people collecting the data described in this paper, the P.I.s for sharing the data and, not the least, the captains and crews on all vessels used during the different surveys. This work has been possible due to support from the EU through IP CARBOOCEAN (511176) and through NOAA's Global
Carbon Cycle Program. Additional support from the International Ocean Carbon Coordination Project IOCCP (Dr. Maria Hood) and the Hanse Institute for Advanced Study (HWK Delmenhorst, Germany) are gratefully acknowledged.

Edited by: V. Gouretski

\section{References}

Anderson, L. G., Chierici, M., Fogelqvist, E., and Johannessen, T.: Flux of anthropogenic carbon into the deep Greenland Sea, J. Geophys. Res., 105(C6), 14339-14345, 2000.

Blindheim, J. and Rey, F.: Water-mass formation and distribution in the Nordic Seas during the 1990s, ICES J. Mar. Sci., 61(5), 846-863, 2004.

Bönisch, G., Blindheim, J., Bullister, J. L., Schlosser, P., and Wallace, D. W. R.: Long-term trends of temperature, salinity, density, and transient tracers in the central Greenland Sea, J. Geophys. Res., 102(C8), 18553-18571, 1997.

$\mathrm{Bu}, \mathrm{X}$. and Warner, M. J.: Solubilities of chlorofluorocarbon 113 in water and seawater, Deep-Sea Res., 42(7), 1151-1161, 1995.

Bullister, J. L. and Weiss, R. F.: Anthropogenic chlorofluoromethanes in the Greenland and Norwegian seas, Science, 221(4607), 265-268, 1983.

Bullister, J. L. and Wisegarver, D. P.: The solubility of carbon tetrachloride in water and seawater, Deep-Sea Res., 45, 1285-1302, 1998.

Doney, S. C. and Bullister, J. L.: A chlorofluorocarbon section in the Eastern North Atlantic, Deep-Sea Res. Part I, 39(11-12), 18571883, 1992.

Falck, E. and Olsen, A.: Nordic Seas dissolved oxygen data in CARINA, Earth Syst. Sci. Data Discuss., 2, 537-553, 2009, http://www.earth-syst-sci-data-discuss.net/2/537/2009/.

Fogelqvist, E.: Determination of volatile halocarbons in seawater, in: Methods of Seawater Analysis, 3rd edition, edited by: Grasshoff, K., Kremling, K., and Ehrhardt, M., 501-519, WileyVCH, 1999.

Huhn, O., Roether, W., Beining, P., and Rose, H.: Validity limits of carbon tetrachloride as an ocean tracer, Deep-Sea Res., 48, 2025-2049, 2001.

Johnson, G. C., Robbins, P. E., and Hufford, G. E.: Systematic adjustments of hydrographic sections for internal consistency, J. Atmos. Ocean. Tech., 18, 1234-1244, 2001.

Jutterström, S., Anderson, L. G., Bates, N. R., Bellerby, R., Johannessen, T., Jones, E. P., Key, R. M., Lin, X., Olsen, A., and Omar, A. M.: Arctic Ocean data in CARINA, Earth Syst. Sci. Data, 2, 71-78, 2010, http://www.earth-syst-sci-data.net/2/71/2010/.

Karstensen, J., Schlosser, P., Wallace, D. W. R., Bullister, J. L., and Blindheim, J.: Water mass formation in the Greenland Sea during the 1990s, J. Geophys. Res., 110, C07022, doi:10.1029/2004JC002510, 2005.

Key, R. M., Tanhua, T., Olsen, A., Hoppema, M., Jutterström, S., Schirnick, C., van Heuven, S., Kozyr, A., Lin, X., Velo, A., Wallace, D. W. R., and Mintrop, L.: The CARINA data synthesis project: introduction and overview, Earth Syst. Sci. Data Discuss., 2, 579-624, 2009,

http://www.earth-syst-sci-data-discuss.net/2/579/2009/. 
Olafsson, J. and Olsen, A.: Nordic Seas nutrients data in CARINA, Earth Syst. Sci. Data Discuss., in preparation, 2010.

Olsen, A.: Nordic Seas total dissolved inorganic carbon data in CARINA, Earth Syst. Sci. Data, 1, 35-43, 2009a, http://www.earth-syst-sci-data.net/1/35/2009/.

Olsen, A.: Nordic Seas total alkalinity data in CARINA, Earth Syst. Sci. Data, 1, 77-86, 2009b, http://www.earth-syst-sci-data.net/1/77/2009/.

Olsen, A., Key, R. M., Jeansson, E., Falck, E., Olafsson, J., van Heuven, S., Skjelvan, I., Omar, A. M., Olsson, K. A., Anderson, L. G., Jutterström, S., Rey, F., Johannessen, T., Bellerby, R. G. J., Blindheim, J., Bullister, J. L., Pfeil, B., Lin, X., Kozyr, A., Schirnick, C., Tanhua, T., and Wallace, D. W. R.: Overview of the Nordic Seas CARINA data and salinity measurements, Earth Syst. Sci. Data, 1, 25-34, 2009,

http://www.earth-syst-sci-data.net/1/25/2009/.

Rhein, M.: Ventilation rates of the Greenland and Norwegian Seas derived from distributions of the chlorofluoromethanes F11 and F12, Deep-Sea Res. A, 38(4), 485-503, 1991.

Roether, W., Klein, B., and Bulsiewicz, K.: Apparent loss of CFC113 in the upper ocean, J. Geophys. Res., 106(C2), 2679-2688, 2001.
Ronski, S. and Budéus, G.: Time series of winter convection in the Greenland Sea, J. Geophys. Res., 110, C04015, doi:10.1029/2004JC002318, 2005.

Steinfeldt, R., Tanhua, T., Bullister, J. L., Key, R. M., Rhein, M., and Khler, J.: Atlantic CFC data in CARINA, Earth Syst. Sci. Data, 2, 1-15, 2010, http://www.earth-syst-sci-data.net/2/1/2010/.

Tanhua, T., van Heuven, S., Key, R. M., Velo, A., Olsen, A., and Schirnick, C.: Quality control procedures and methods of the CARINA database, Earth Syst. Sci. Data, 2, 35-49, 2010, http://www.earth-syst-sci-data.net/2/35/2010/.

Tanhua, T., Waugh, D. W. and Wallace, D. W. R.: Use of $\mathrm{SF}_{6}$ to estimate anthropogenic $\mathrm{CO}_{2}$ in the upper ocean, J. Geophys. Res., 113, C04037, doi:10.1029/2007JC004416, 2008.

Walker, S. J., Weiss, R. F., and Salameh, P. K.: Reconstructed histories of the annual mean atmospheric mole fractions for the halocarbons CFC-11, CFC-12, CFC-113 and carbon tetrachloride, J. Geophys. Res., 105(C6), 14285-14296, 2000.

Warner, M. J. and Weiss, R. F.: Solubilities of chlorofluorocarbons 11 and 12 in water and seawater, Deep-Sea Res., 32(12), 14851497, 1985. 